WANL-TMI-175I

\title{
PARAMETRIC ANALYSIS OF HEAT PIPES
}

\section{MASTER}

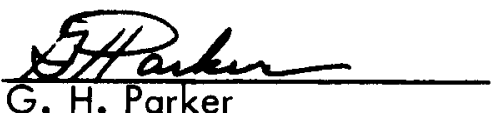

Systems Engineering

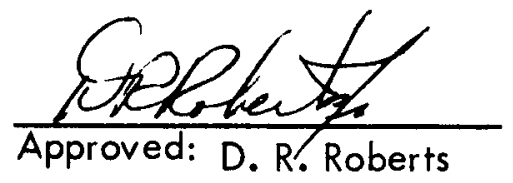

Supv., System Design \& Analysis

Systems Engineering

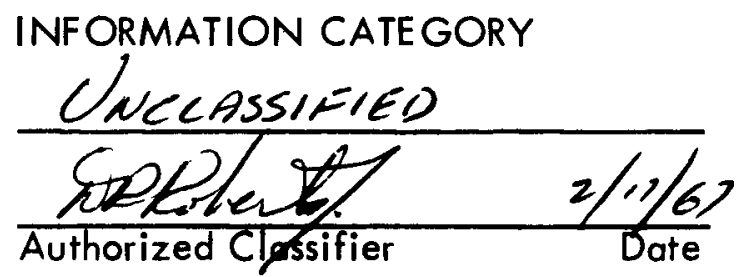




\section{DISCLAIMER}

This report was prepared as an account of work sponsored by an agency of the United States Government. Neither the United States Government nor any agency Thereof, nor any of their employees, makes any warranty, express or implied, or assumes any legal liability or responsibility for the accuracy, completeness, or usefulness of any information, apparatus, product, or process disclosed, or represents that its use would not infringe privately owned rights. Reference herein to any specific commercial product, process, or service by trade name, trademark, manufacturer, or otherwise does not necessarily constitute or imply its endorsement, recommendation, or favoring by the United States Government or any agency thereof. The views and opinions of authors expressed herein do not necessarily state or reflect those of the United States Government or any agency thereof. 


\section{DISCLAIMER}

Portions of this document may be illegible in electronic image products. Images are produced from the best available original document. 


\section{CONTENTS}

I. SUMMARY AND RECOMMENDATIONS

II. INTRODUCTION

III. PERFORMANCE CAPABILITIES AND LIMITATIONS

A. Principles of Operation

B. Choice of Working Fluids

C. Definition of Limiting Criteria

D. Parametric Analysis

IV. REFERENCES

V. APPENDICES

A. Derivation of Equivalent Pore Radius

B. Integration of Liquid Pressure Drop

C. Design Example 


\section{SUMMARY}

This TMI assesses the performance capabilities and limitations of heat pipes through a parametric analysis and, to a limited extent, comparison with experimental heat pipe results. A number of parametric curves are presented to provide quantitative insight regarding the physical phenomena that govern heat pipe operation and to provide heat pipe design guidelines. The principles of heat pipe operation are briefly discussed along with a concise history of their development.

For operation at a specified temperature level, the trade-off factors involved in selecting a heat pipe working fluid are dominated by the vapor pressure curves of candidate fluids. Other primary fluid properties related to fluid selection are latent heat of vaporization and surface tension. Two principal criteria appear to limit the performance capabilities of heat pipes. One involves the ability of the capillary wick to keep the evaporating-condensing fluid in circulation. This ability is conveniently assessed by the pressure balance: the available capillary pumping must equal the summation of pressure drops in the circulating fluid. Parametric curves are presented for the capillary head and the pressure drops that occur because of (1) gravity, (2) viscous drag of the liquid within the wick, and (3) motion of the vapor from the evaporator to the condenser. Calculation of each of the above factors is straightforward with the exception of the pressure profile in the vapor. A digital computer code has been used to numerically integrate the vapor addition in the evaporator and removal in the condenser. Results from the code have predicted substantial pressure recoveries in the condenser region and have provided more optimistic performance predictions than did earlier analytical models.

The other performance limit is the constraint imposed on radial heat flux. A heat flux map has been prepared to relate pipe diameter and heat input to flux (Figure 17). For conservative design purposes, maximum evaporating heat fluxes of $1.5 \pm 0.5\left(10^{5}\right) \mathrm{Btu} / \mathrm{hr}$. $-\mathrm{ft}^{2}$. are being recommended. This range was selected after contrasting the phenomena that occur in heat pipes at the liquid-vapor interface with conventional experiments with boiling and condensing 
alkali metals. In heat pipes, the vaporization of the working fluid apparently should be confined to surface evaporation below the nucleate boiling region so that formation of hot spots in the wick can be avoided. Heat fluxes that have been obtained in heat pipe condensers appear to exceed those of conventional condensation experiments. This conclusion has been supported by a theoretical analysis that predicted improvements over the classical Nusselt theory for condensation occurring on a porous surface with suction.

It is recommended that future in-house heat pipe efforts at WANL concentrate in the following areas:

1. The problems associated with lifetime and reliability should be explored. Emphasis should be placed on the materials' compatibility of container, wick, and working fluid, and on minimizing corrosion and solubility of the wick. A detailed investigation of wick configuration should be made to determine whether any type (e.g., slotted) is clearly superior.

2. The transient conditions that occur in startup and shutdown should be investigated to determine whether transients impose significant design constraints.

3. Additional experimental work should be performed to determine more precisely the limits imposed by heat flux and pressure balance and to verify that these are in fact the most significant limiting criteria.

\section{INTRODUCTION}

Considerable interest currently exists in heat transport devices that use capillarity for pumping of the working fluid. Grover, et. al., at Los Alamos are generally credited with the first publication $^{(1)}$ describing these devices. The earliest known disclosure of the concept was filed by D. Thompson at WANL in $1960^{(2)}$. Devices employing capillary wicking action to drive a two-phase evaporating-condensing working fluid are generally called "heat pipes". A special application in space radiators has been termed "vapor chamber fin". 
In 1964, Grover, et. al., reported the operation of heat pipes using $1500^{\circ} \mathrm{F}$ sodium as the working fluid. It should be noted that these original heat pipes were designed, built, and operated prior to extensive analytical modeling of heat pipe performance. In 1965, Cotter ${ }^{(3)}$ published a theory of heat pipes; his models have been generally used by other groups interested in quantitative design of heat pipes.

Interest in heat pipes and vapor chamber fins has been increasing largely because of their potential attractiveness in space power systems. A heat pipe conference was held on June 1, 1966 at the Sandia Laboratories. The proceedings of this conference ${ }^{(4)}$ represent the most recent state-of-the-art report of heat pipe development.

The objectives of the in-house heat pipe analysis at WANL have been (1) to perform a parametric analysis that will aid in the design of heat pipes, and (2) to estimate the performance capabilities and limitations of heat pipes, particularly with regard to the maximum amount of heat that can be transported. The analysis has been primarily directed toward the $1000^{\circ} \mathrm{F}$ to $1200^{\circ} \mathrm{F}$ temperature range because of the potential use of heat pipes with tubular thermoelectric modules. This report presents the results of the parametric analysis, discusses the performance limitations, and recommends areas of future investigation at WANL.

\section{PERFORMANCE CAPABILITIES AND LIMITATIONS}

\section{A. PRINCIPLES OF OPERATION}

The ability of a heat pipe to transport heat in a nearly isothermal fashion is governed by the evaporation and condensation of the working fluid in specified regions of the pipe. Transport of heat is accomplished by vaporized fluid moving from an evaporating region to a condensing region where the fluid's latent heat is released in condensation. A significant distinction between a heat pipe and a natural circulation loop or reflux condenser is in the technique for circulation of the fluid. By using a wicking structure to return the condensate to the evaporating region, the heat pipe is inherently able to operate in the absence of gravity, and within limits, 


\section{(w)

against gravity. Under either condition, an important aspect of heat pipe design involves the choice of a wick that will provide adequate capillary action to balance the pressure losses that occur in the liquid and vapor. Quantitative design considerations of these factors are presented in this report.

\section{B. CHOICE OF WORKING FLUID}

The choice of working fluid in a heat pipe is dependent on several physical properties of the fluid and on compatibility of fluid with the wicking structure. The most significant properties are as follows: vapor pressure, latent heat of vaporization, surface tension, and wetting ability. Other important properties are thermal conductivity and viscosity of vapor and liquid.

The vapor pressure curve dictates the temperature range of applicability for a given fluid. Generally, a fluid should be used in a steeply sloped region of its vapor pressure curve to effect small temperature differences in the heat pipe. For example, at $1100^{\circ} \mathrm{F}$, potassium has more favorable vapor pressure characteristics than does sodium, as can be seen from Figure 1. The vapor pressure curves of several potential high temperature working fluids are shown in Figure 2. In addition to being steeply sloped at a specified operating temperature, the vapor pressure should be reasonably high, at least several psi. A low vapor pressure would result in low vapor densities and high pressure drops in the moving vapor.

A high latent heat is desirable because the mass flow rate required to transport a given amount of heat is inversely proportional to the latent heat. A comparison of the relative magnitudes of the latent heats of several liquid metals in their respective appropriate temperature range is shown in Figure 3. Although lithium is clearly superior in latent heat to the other metals shown, its use would be limited to applications above 1700 or $1800^{\circ} \mathrm{F}$ because of its vapor pressure curve, Figure 2.

The working fluid should have a high surface tension and should wet the wick material well to effect good capillary action. Figure 4 compares the relative values of surface tension for some candidate liquid metals. Wetting ability, a function not only of surface tension, but of the two 
materials in contact, has not been investigated in this study. The parametric analyses will assume that perfect wetting can be obtained, i.e., $\cos \theta=1$, where $\theta$ is the contact angle of the liquid-solid miniscus. For realistic situations where wetting is imperfect, the capillary head will be attenuated by appropriate values of $\cos \theta<1$.

\section{DEFINITION OF LIMITING CRITERIA}

Several criteria appear to limit the performance capabilities of heat pipes. Two of these are related to the maximum heat transport ability of the pipe. The first criterion has already been discussed briefly: the pressure drops must not exceed the capillary wicking ability.

A second criterion is related to the maximum heat fluxes that can be tolerated in the evaporator and condenser, respectively. In the evaporator, the onset of boiling within the liquid can disrupt the wicking action and result in the formation of hot spots with resultant large temperature rises. In the condenser, a limit may also exist for condensing heat flux. Considerable progress has been made in the empirical knowledge of boiling and condensing heat transfer coefficients of liquid metals, but uncertainties do remain in precision. This report estimates the performance limits related to boiling and condensing by bracketing the available experimental results from heat pipe tests and other applicable liquid metal tests.

Other performance limits of heat pipes are related to lifetime, reliability, and startup transients. Materials compatibility between the working fluid, wick, and container must be assured to avoid corrosion. The solubility of wicking materials into the fluid has been reported ${ }^{(5)}$ with deposition in the evaporator eventually clogging the wick pores. The AEC is currently sponsoring a devel-' opment program ${ }^{(6)}$ to demonstrate reliability of heat pipes by life testing.

The lifetime, reliability, or transient criteria are not evaluated in this report. These factors should, however, be considered in future heat pipe efforts at WANL. 


\section{PARAMETRIC ANALYSIS}

1. Pressure Balance Limitation

The design of a heat pipe to meet a specified set of conditions can be initially scoped by stating the pressure drop criterion:

$\left[\begin{array}{c}\text { Available Capillary } \\ \text { Pressure Head }\end{array}\right] \geq\left[\begin{array}{c}\text { Viscous Drop } \\ \text { in Liquid }\end{array}\right]+\left[\begin{array}{c}\text { Viscous and Inertial } \\ \text { Drops in Vapor }\end{array}\right]+\left[\begin{array}{c}\text { Gravitational } \\ \text { Drops (if any) }\end{array}\right]$

(a) Capillary Head

Each of these terms can be temporarily isolated for parametric consideration of their order of magnitude. Consider first the available head from the capillary wick. The pressure difference from surface tension for a liquid in an ideal cylindrical capillary tube of radius $r_{c}$ and wetting angle $\theta$ is $\frac{2 \gamma \cos \theta}{r_{c}}$, where $\gamma$ is the surface tension. The magnitudes of available capillary heads for several liquid metals are shown in Figure 5. Although the calculations have been based on cylindrical capillary pores, these curves can be used with other wick configurations such as slotted walls by computing the "equivalent hydraulic pore radius". A derivation for this procedure is contained in Appendix A.

Figure 5, then, contains key information about the capillary pumping of heat pipes. When a design is being considered, the sum of the various pressure drops must not exceed the available capillary pumping.

\section{(b) Gravitational Pressure Drop in Wick}

Horizontal operation of a heat pipe is approximately equivalent to operation in space, i.e., the gravitational pressure drop of the liquid in the wick is non-existent. When inclined from the horizontal or in the vertical position on earth, however, the gravitational drop can be significant. Figure 6 shows the magnitude of this effect for $\mathrm{Na}, \mathrm{K}, \mathrm{Li}$, and $\mathrm{Hg}$. For example, $\mathrm{Na}$ in the vertical position imposes $\sim 0.35$ psi 
per foot of pipe from its own weight. Whenever heat pipes are to be designed for gravity-free or horizontal operation, this effect can be neglected. For other conditions, however, it should be considered.

\section{(c) Viscous Pressure Drop in Wick}

A calculational model for the viscous drag of the liquid in heat pipe wicks has been derived by Cotter ${ }^{(3)}$. This model is based on the Hagen-Poiseville law, and describes the axial pressure gradient in the liquid at any point along the wick. For the usual condition where the heat input in the evaporator is axially uniform (constant watts/inch), the model is easily integrable to calculate the pressure drop in the wick for a specified interval or for the total heat pipe length. This integration is given in Appendix B.

Parametric results of the wick pressure drop are presented in Figure 7. Ideal cylindrical capillary pores are the basic model; other geometries can be used by computing the equivalent pore radius by the method of Appendix $A$.

\section{(d) Pressure Drop in Vapor}

The transport of vapor from the evaporator to the condenser is perhaps the most complex aspect of a heat pipe to analytically model and evaluate. The complexity is, in great part, due to the continuing addition of vapor along the axial length of the evaporator and corresponding vapor removal in the condenser.

A model for the pressure drop in the vapor along the length of the pipe has been devised by Cotter ${ }^{(3)}$. His model is based on approximate solutions of the NavierStokes equations while treating the evaporating and condensing processes as equivalent to pipe flow with in jection and suction through a porous wall. The model defines two regions: conditions where viscous forces dominate, and conditions where inertial forces dominate. The latter case is more likely to be encountered in practical heat pipes. Cotter's approximate solution of the 
Navier-Stokes equations for the case where inertial forces dominate is expressed by equation 1:

$$
\Delta P_{v}=P_{v}(z)-P_{v}(0)=\frac{\left(1-\frac{4}{\pi^{2}}\right) Q^{2}}{8 \rho_{v} r_{v}^{4} L^{2}}
$$

Note that this model is independent of the heat pipe length and the vapor viscosity. The radius of the cylindrical vapor passage is $r_{v}$ and $P_{V}$ is the density of the vapor. Because incompressible flow is assumed in Cotter's model, the vapor density along the length is taken as constant. The ratio $Q / L$ represents the total mass flow rate of vapor $\dot{m}_{v}\left(\frac{l b}{\sec }\right)=\frac{Q}{L}\left(\frac{B+u / s e c}{B+v / l b}\right)$, where $L$ is the latent heat. A pertinent feature of Cotter's model is the axial profile of pressure in the vapor, shown in Figure 8. Deceleration of the condensing vapor results in a pressure recovery in the heat pipe condenser. Cotter's model predicts that the maximum extent of recovery is fixed ot $\frac{4}{\pi 2}=40.5 \%$ of the drop that occurred in the evaporator regardless of the amount of heat being transported. Therefore, the profile shown in Figure 8 represents the pressure distribution of vapor for any case dominated by inertial forces.

A digital computer code has been written at WANL by Hanson ${ }^{(7)}$ that considers compressible flow of the vapor and therefore treats the vapor density as a variable, determined from iterative enthalpy calculations. Results from the code have provided an interesting comparison to Cotter's model.

Consider a 0.7-inch ID heat pipe with evaporator and condenser each 5 inches long and separated by a 1 -inch insulated section, using sodium at $1200^{\circ} \mathrm{F}$. Parametric results from the code are shown in Figures 9 and 10 for heat inputs ranging from 0.1 to $3.0 \mathrm{Kwt}$. For $0.1 \mathrm{Kwt}$ input, the code computes a small pressure drop in the vapor with no recovery, implying the dominance of viscous forces. For higher heat inputs, however, recovery appears, therefore, implying the dominance of inertial 
forces. The significant departure between Cotter's model is the following: as heat input increases, the code predicts a higher percent pressure recovery in the condenser compared to the fixed $40.5 \%$ recovery predicted by Cotter. The extent of recovery is shown in Figure 11 to be greater than $90 \%$ for heat inputs exceeding $3 \mathrm{Kwt}$. Therefore, for high heat inputs, the net end-to-end pressure difference in the heat pipe vapor is less than $10 \%$ of the gross drop in the evaporator.

If the drop in the evaporator alone is considered for the above cases, the code predictions and Cotter's predictions indicate excellent agreement, as can be seen in Figure 12. This good agreement of results in the evaporator indicates that the two models differ only in the extent of pressure recovery. This difference has been recently discussed with Dr. Cotter ${ }^{(8)}$, and he stated that his more recent analyses have indicated variable pressure recoveries in the vapor. Qualitatively, he gave verbal support to the trend shown in Figures 9 and 10.

If the end-to-end net pressure drop results are used in the pressure balance criterion, more optimistic performance capabilities will be predicted for heat pipes than with the fixed recovery model. If pressure recovery were neglected altogether, a very conservative pressure balance criterion would exist. These optimistic and pessimistic models can serve to provide brackets for the pressure drop in the vapor. These brackets are shown in Figure 13 parametrically for heat pipes using sodium at $1200^{\circ} \mathrm{F}$.

In conjunction with Figure 13, the temperature dependence of the pressure drop in the vapor can be assessed in Figure 14, which is normalized to $1200^{\circ} \mathrm{F}$ sodium. Lower operating temperatures will result in lower vapor densities and higher pressure drops. The temperature dependence of potassium is shown, also normalized to $1200^{\circ} \mathrm{F}$ sodium.

Additional insight into the temperature dependence can be gained by examining the maximum vapor velocities that occur at the evaporator-condenser interface. 
The significant difference between velocities at $1200^{\circ} \mathrm{F}$ and $1400^{\circ} \mathrm{F}$ can be seen in Figure 15. The dotted line at $1200^{\circ} \mathrm{F}$ shows the effect of treating the vapor as a compressible fluid. The deviation between the incompressible and compressible lines becomes significant between Mach numbers 0.2 and 0.3 as would be expected. Figure 16 displays variations in vapor velocity with heat pipe diameter and temperature. The dash limiting line indicates where compressibility enters its effects.

\section{Boiling and Condensing Limits}

The processes of evaporating and condensing of the working fluid of a heat pipe can be compared with the phenomena that occur in conventional two-phase boiling and condensing equipment. The objective of heat pipes, however, is to transport the heat with very small temperature differences. The mechanism of effecting a nearly isothermal profile in a heat pipe is to utilize the fluids latent heat as the primary mode of heat transfer. Thus, a contrast exists between the design objectives of heat pipes and those of conventional boilers, i.e., boilers rely heavily on a convective process in conjunction with the latent heat. This is true in either pool or flow boiling because the motion of bubbles provides convection and dominates the heat transfer process, while latent heat contributes only a few percent of the total heat transport associated with the phase change ${ }^{(9)}$. In contrast, heat pipes do not emply the convective of bubbles for a significant fraction of the heat transport. Therefore, if latent heat is the predominant contributor to the total process, then the working fluid should be limited to surface evaporation without the formation of bubbles in the wick. It is not the intention of this report to examine microscopically the boiling or condensing phenomena in heat pipes or in conventional two-phase equipment. The approach instead is to employ the macroscopic empirical knowledge of boiling and condensing heat transfer wherever applicable, and to use the data to provide guidelines for estimating limits of heat pipe operation.

\section{(a) Evaporating Limits}

Boiling data typically indicate a peak heat flux for the nucleate boiling region where the temperature differences between wall and liquid saturation are in the range of 50 to $70^{\circ} \mathrm{F}$, with corresponding heat fluxes between $10^{5}$ and $10^{6} \mathrm{Btu} / \mathrm{hr}-\mathrm{ft}^{2}$. 
Although data for liquid metals are sparse compared to water or alcohols, there are indications in the literature $(9,10,11)$ that trends in nucleate boiling of liquid metals are very similar to those of water.

Evaporating heat fluxes have been reported in operating heat pipes and some representative values are summarized in Table 1. These values do not, in all cases, represent limits, i.e., fluxes at which the heat pipes became unstable. It appears from the heat pipe data that fluxes can be obtained at least as large as the fluxes that hove been reported for liquid metal boiling experiments.

\section{TABLE I}

Evaporative Heat Fluxes Reported in Heat Pipes

\begin{tabular}{|c|c|c|c|c|}
\hline \multirow{2}{*}{$\begin{array}{c}\text { Reported } \\
\text { By }\end{array}$} & \multirow{2}{*}{$\begin{array}{c}\text { Fluid and } \\
\text { Temperature }\end{array}$} & \multicolumn{2}{|c|}{ Heat Flux Achieved } & \multirow{2}{*}{} \\
\cline { 3 - 4 } & Watts $/ \mathrm{cm}^{2}$ & Btu $/ \mathrm{hr} .-\mathrm{ft}$. & Reference \\
\hline RCA & Li at $1200^{\circ} \mathrm{C}$ & 94.6 & $.3 .1\left(10^{5}\right)$ & $(12)$ \\
RCA & Li at $1450^{\circ} \mathrm{C}$ & 253 & $8.4\left(10^{5}\right)$ & $(12)$ \\
LASL & $\mathrm{K}$ at $725^{\circ} \mathrm{C}$ & 69 & $2.3\left(10^{5}\right)$ & $(5)$ \\
LASL & Na at $850^{\circ} \mathrm{C}$ & 104 & $3.5\left(10^{5}\right)$ & $(5)$ \\
LASL & Li at $1300^{\circ} \mathrm{C}$ & 200 & $6.65\left(10^{5}\right)$ & $(13)$ \\
LASL & Ag at $2000^{\circ} \mathrm{C}$ & 400 & $1.3\left(10^{6}\right)$ & $(13$ \\
\hline
\end{tabular}

The extent to which boiling may have occurred in the heat pipe wicks (in lieu of surface evaporation) to obtain the heat fluxes given in Table I is not known. In some cases, the heat pipes did fail at the specified heat fluxes. The mechanism of failure is not well understood, however. One hypothesis, attributed to boiling, is burnout or formation of hot spots in the wick. Another hypothesis is that the pressure drop condition, discussed earlier in this report, may have been exceeded. It is conceivable that interaction of these two phenomena may have contributed superimposed effects. 
The prediction of explicit heat flux limits in a heat pipe would be fraught with pitfalls because of the uncertainties associated with liquid metal two-phase heat transfer. Nevertheless, conservative values for upper bounds can be recommended for heat pipe design purposes. A heat flux map is shown in Figure 17 to relate the radial flux to pipe size. For example, if a requirement existed to input $5 \mathrm{Kwt}$ over an axial length of 6 inches $(10 \mathrm{Kwt} / \mathrm{ft}$.) with a heat pipe having an inner diameter of 1.0 inch, the corresponding heat flux would be $1.3\left(10^{5}\right) \mathrm{Btu} / \mathrm{hr} . \mathrm{ft}^{2}$. The range of maximum flux being recommended is $10^{5}$ to $2\left(10^{5}\right)$ Btu $/ \mathrm{hr} . \mathrm{ft}^{2}$., and the heat pipe may have a reasonable probability of successfully operating under the above conditions. If, however, the requirement was specified for $40 \mathrm{~K}$ wt with the same pipe $(80 \mathrm{Kwt} / \mathrm{ft}$.$) , the heat flux would exceed 10^{6} \mathrm{Btu} / \mathrm{hr} . \mathrm{ft}^{2}$. . For the more "conventional" working fluids, $\mathrm{K}$ or $\mathrm{Na}$, a heat pipe would probably not be able to attain a heat flux of this magnitude. Explicit limits of heat flux capabilities can be determined only after a reasonably large body of experimental heat pipe operating data has been obtained and evaluated statistically.

\section{(b) Condensing Limits}

A reasonable body of experimental knowledge of the condensing heat transfer capabilities of water and organic fluids has been accumulated during recent decades. The experimental results have generally verified Nusselt condensing theory; variations in results have been accounted for by considering surface conditions, orientation, temperature range, etc. The inherently superior heat transfer ability of dropwise condensation compared to filmwise condensation has been widely demonstrated.

Empirical knowledge of the condensing heat transfer capabilities of alkali metals in general, and heat pipe applications in particular, is much less advanced than with conventional fluids. The data available have generally been below the Nusselt theory, with a few exceptions. One trend reported in the literature, based on experiments with $\mathrm{K}, \mathrm{Na}$, and $\mathrm{Hg}$, has indicated decreasing $\mathrm{h}$ with increasing $\Delta T=\left(T_{\text {sat }}-T_{W}\right)$, implying a nearly constant heat flux ${ }^{(10)}$. 
For Na and $K$, the reported heat fluxes hove not exceeded $2\left(10^{4}\right)$ Btu/hr.ft ${ }^{2}$. Because condensing metal vapors are normally used in containers that are wet by the fluid, the mechanism probably is film-type condensation. Thus, highly optimistic rates of heat transfer with condensing metals should not be expected. Bonilla. (11) has reported an effort to compute a variable condensotion coefficient that could be correlated with significant factors such as surface condition, temperature, etc. Usable evaluation of such a coefficient, however, may be several years away.

The heat fluxes that have been obtained in the condensers of heat pipes are sur prisingly high when considered in conjunction with the general data as discussed above. RCA has reported the attainment of a condensing flux of $2\left(10^{5}\right) \mathrm{Btu} / \mathrm{hr} . \mathrm{ft}$. in a heat pipe in which condenser heat flux concentration was the objective ${ }^{(12)}$. Therefore, heat pipes ore apparently able to achieve heat fluxes in the condenser that are nearly an order of magnitude greater than other data obtained from condensing metal experiments. This result has been independently verified in an analysis by Franket and Bankoff ${ }^{(.14)}$. This analysis considered condensation of a vapor onto a surface having a suction velocity, a condition that approximates a heat pipe because of its wicking action. The analytical solution for a zero gravity case qualitatively indicated heat transfer rates greater than the classical Nusselt solution.

In summary, condenser heat fluxes in heat pipes appear to be greater than those obtained by other experiments with condensing metals. The limited amount of data, however, precludes the determination of explicit limits. For present design purposes, a maximum condensing flux of $10^{5} \mathrm{Btu} / \mathrm{hr} . \mathrm{ft}^{2}$ is recommended. Please note that Figure 17 is applicable for condenser as well as evaporator design considerations. 


\section{REFERENCES}

1. G. M. Grover, T. P. Cotter, and G. F. Erickson, "Structures of Very High Thermal Conductance", J. Appl. Phys. 35, 1990 (1964).

2. D. C. Thompson, Patent Disclosure No. 48148, February 10, 1960.

3. T. P. Cotter, "Theory of Heat Pipes", LA-3246-MS, 1965.

4. Proceeding of the Joint Atomic Energy Commission/Sandia Laboratories Heat Pipe Conference, SC-M-66-623, October 1966.

5. T. P. Cotter, et. al., "Status Report on Theory and Experiments on Heat Pipes at Los Alamos", Thermionics Specialists Conference, 1965.

6. Development of a $600^{\circ} \mathrm{C}$ Heat Pipe Assembly, A00-3507-2, September, 1966 (CDI).

7. J. P. Hanson, "Heat Pipe Design Code", July, 1966.

8. G. H. Parker, telecon with T. P. Cotter, January 25, 1967.

9. L. S. Tong, "Boiling Heat Transfer and Two Phase Flow", Wiley, 1965.

10. SNAP Technology Handbook, Vol. I, Liquid Metals, NAA-SR-8617, April, 1964.

11. C. Bonilla and R. Brooks, "Liquid Metal Heat Transfer", Nucleonics Volume 22, No. 3, March, 1964.

12. R. B. Hall, "Heat Pipe Experiments", Thermionics Specialists Conference 1965, (unclassified).

13. J. Deverall and J. Kemma, "High Thermal Conductance Devices Utilizing the Boiling of Lithium or Silver", LA-3211, April,1965.

14. N. Frankel and S. Bankoff, "Laminar Film Condensation on a Porous Horizontal Tube with Uniform Suction Velocity", Journal of Heat Transfer, Volume 87, Series C, February, 1965. 
FIG 1

COMPARISON OF VAPOR PRESSURES OF SODIUM AND POTASSIUM

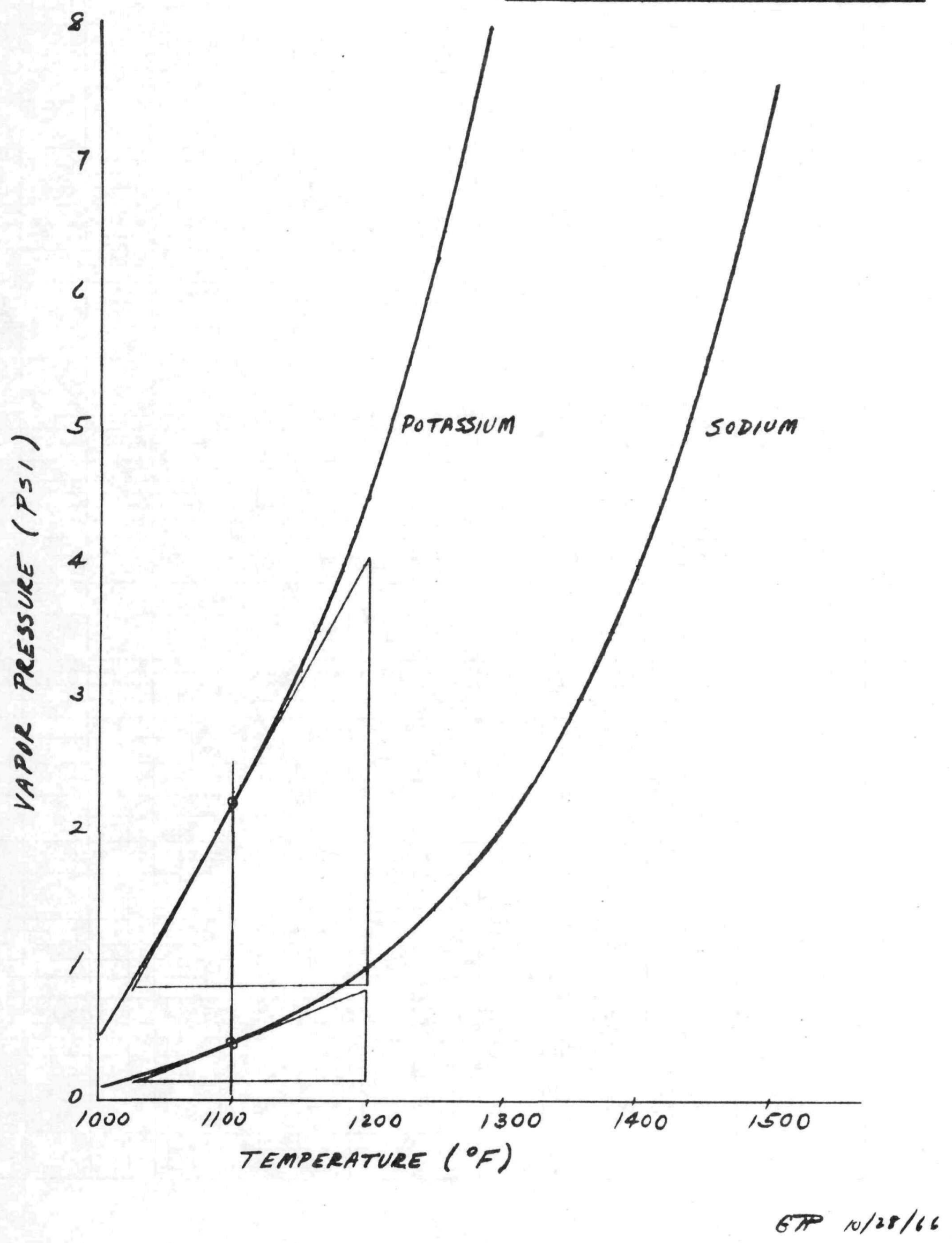




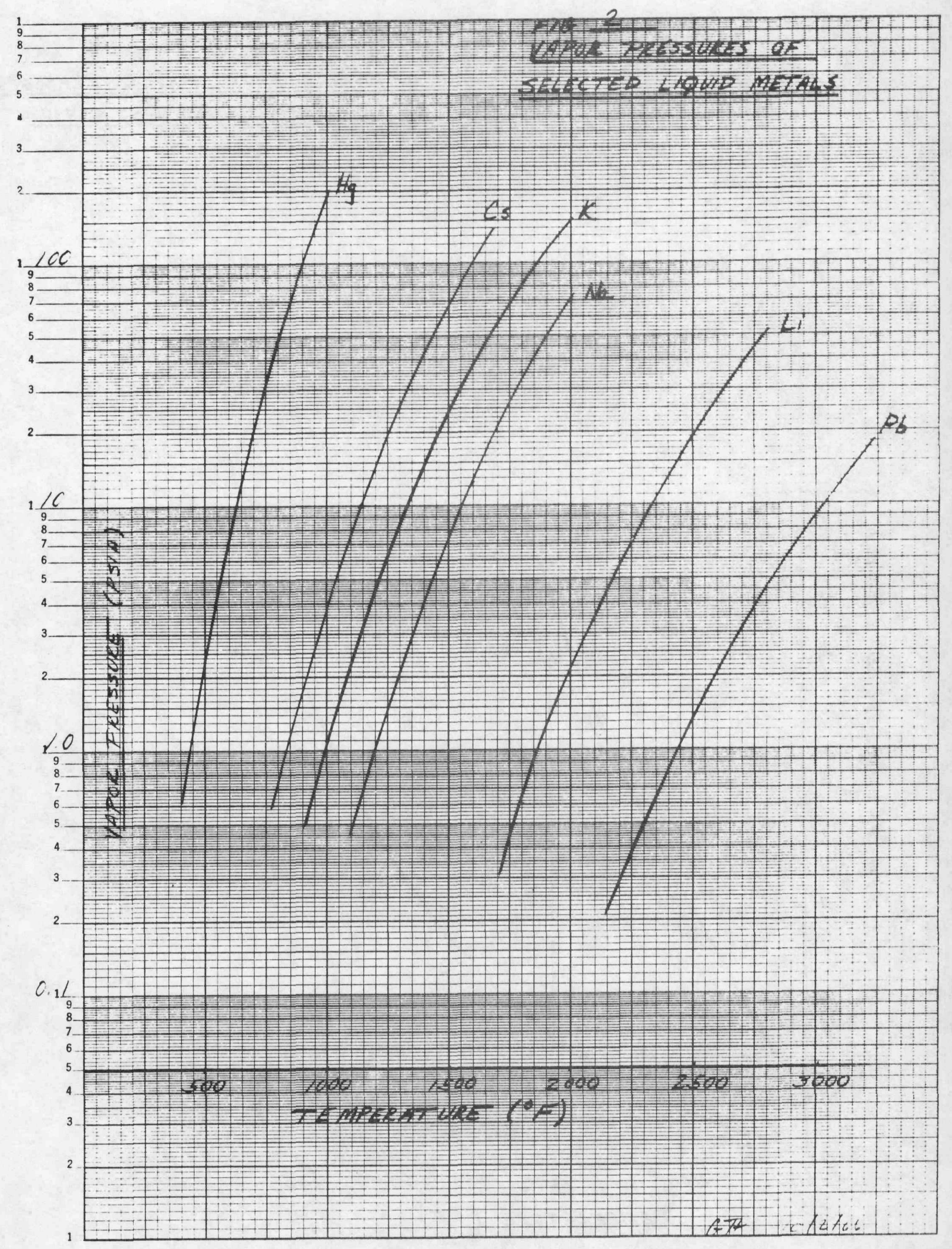




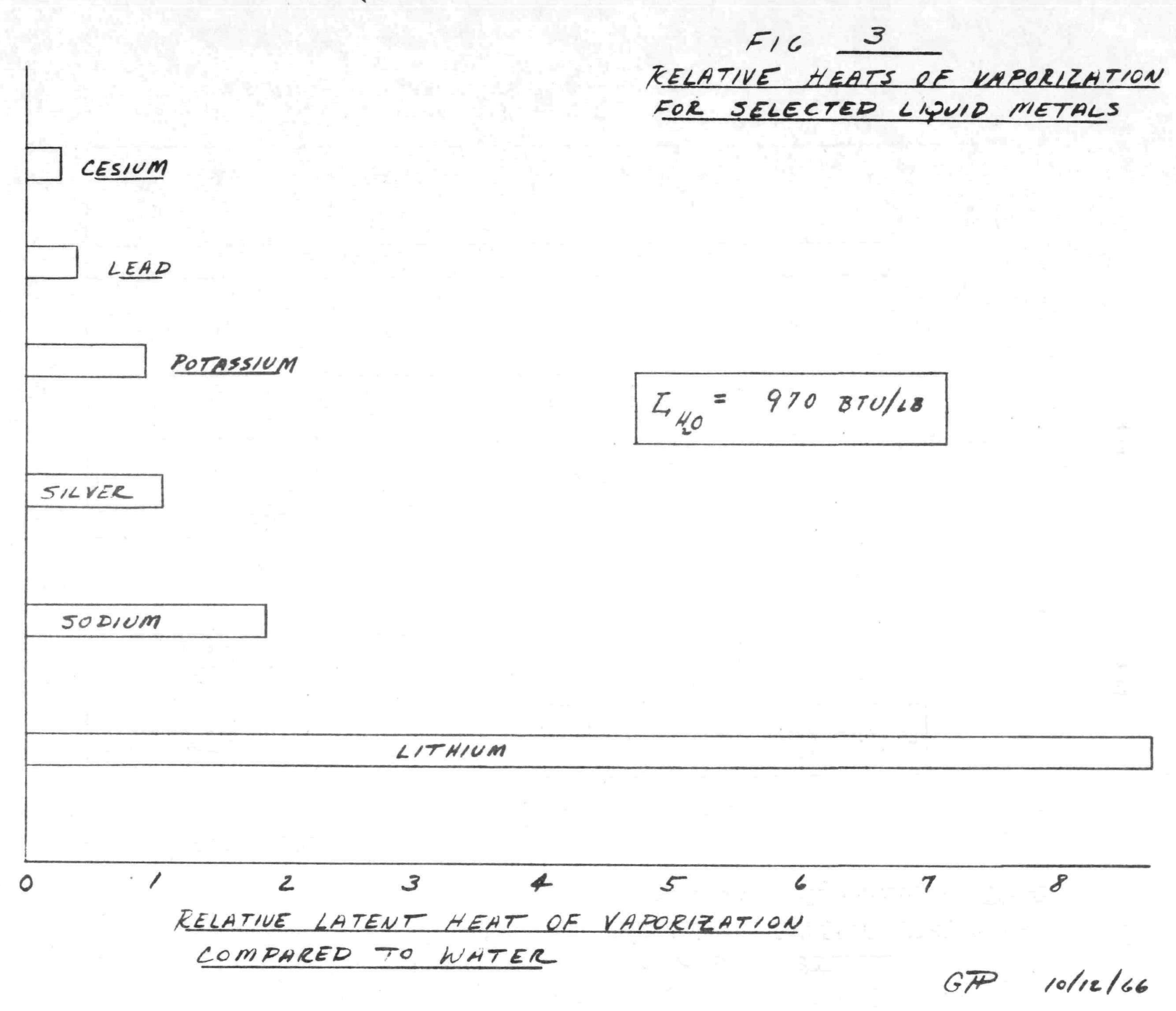




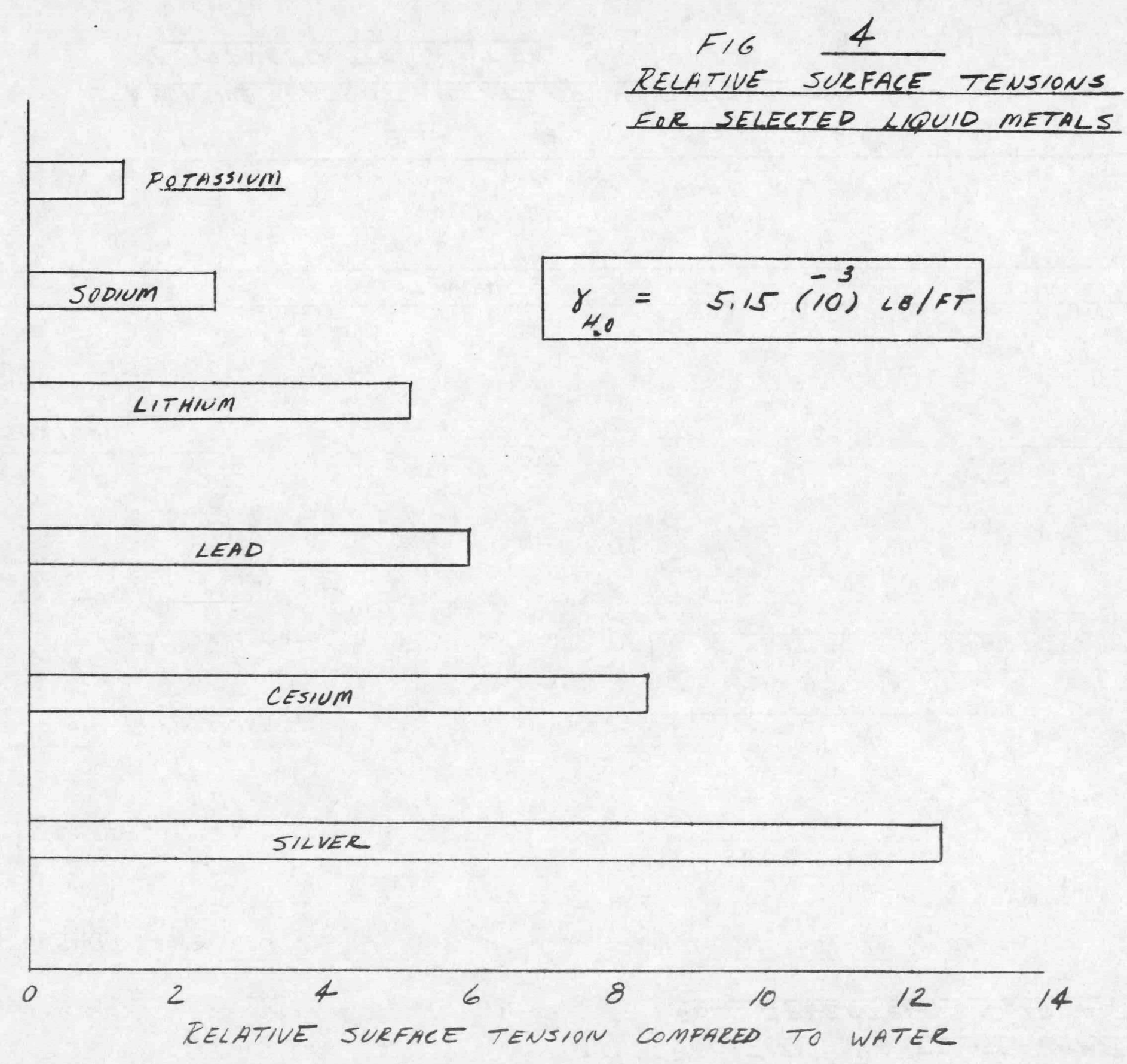


-

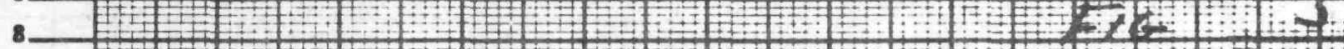

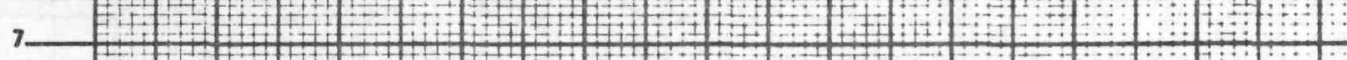

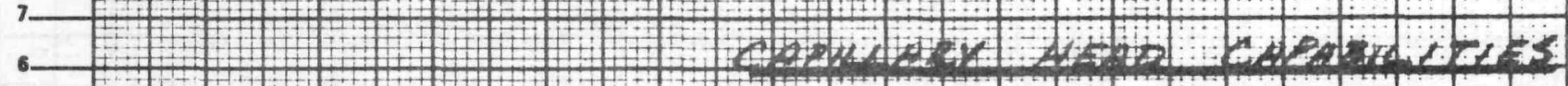

5

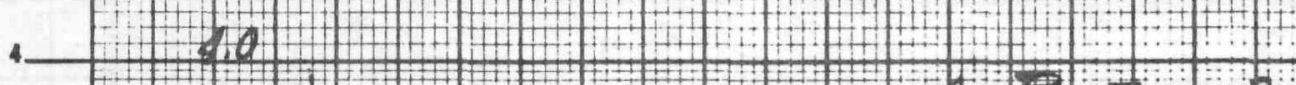

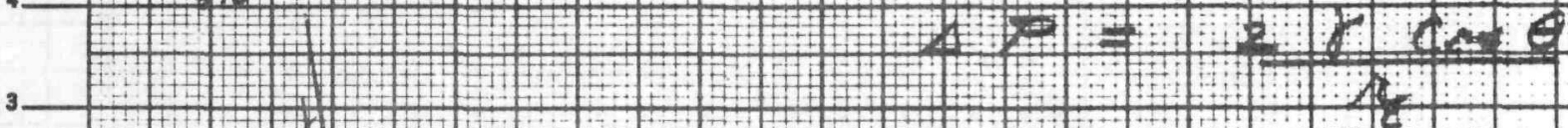

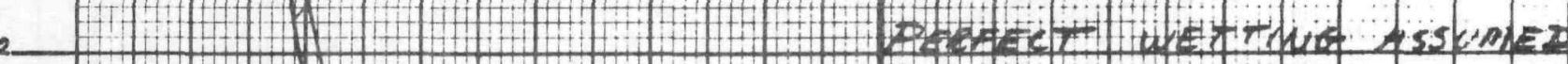

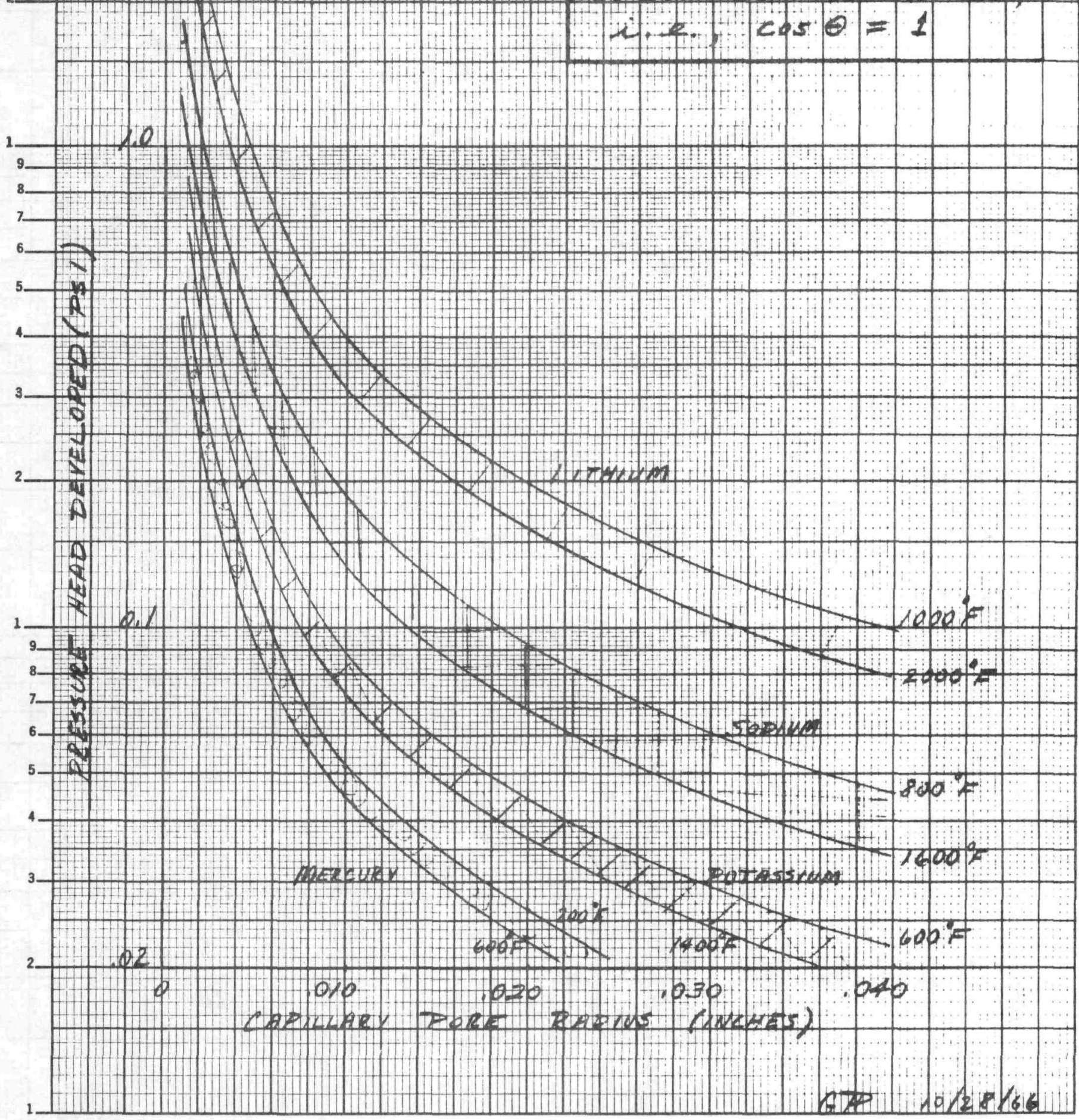




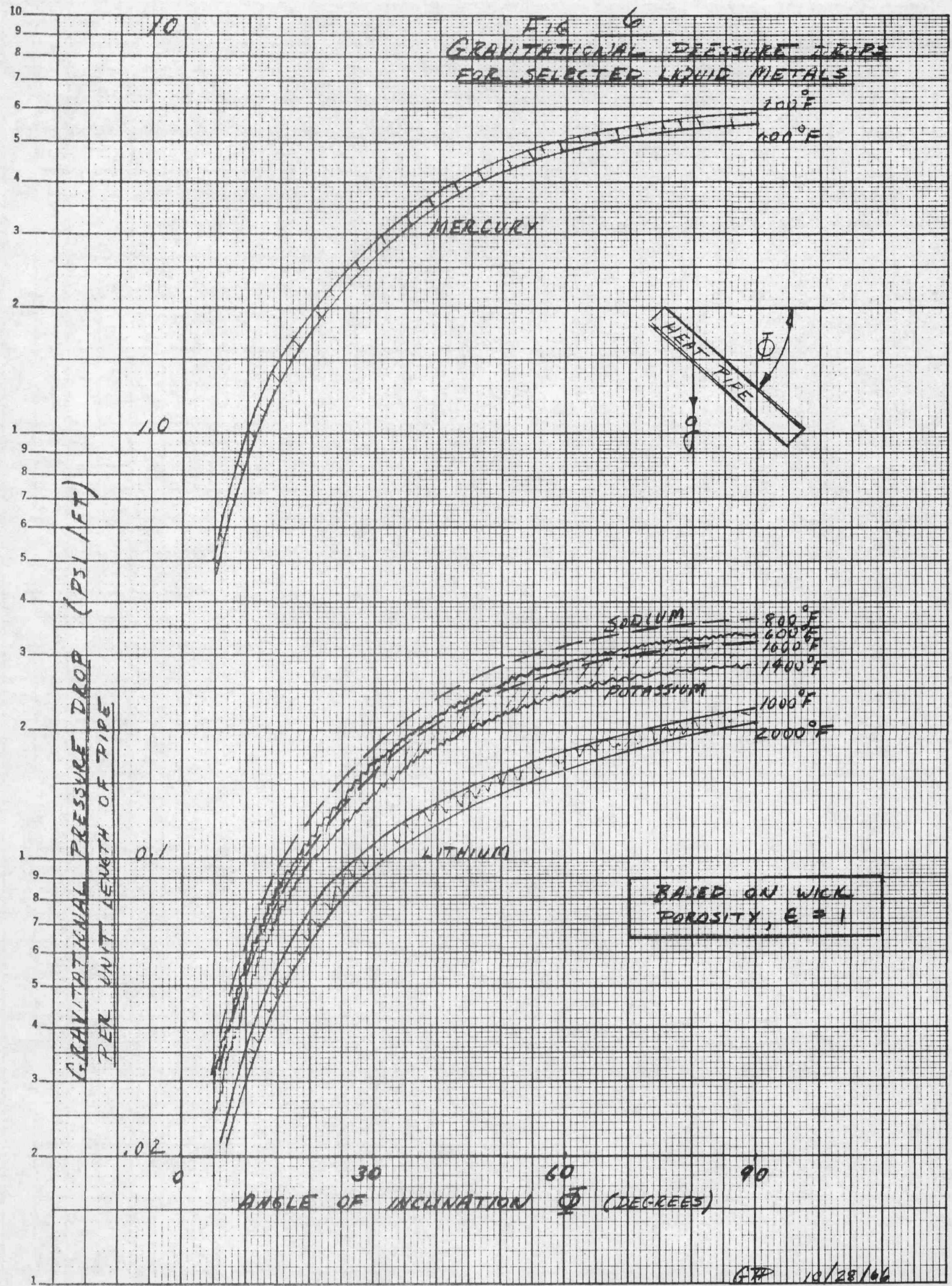




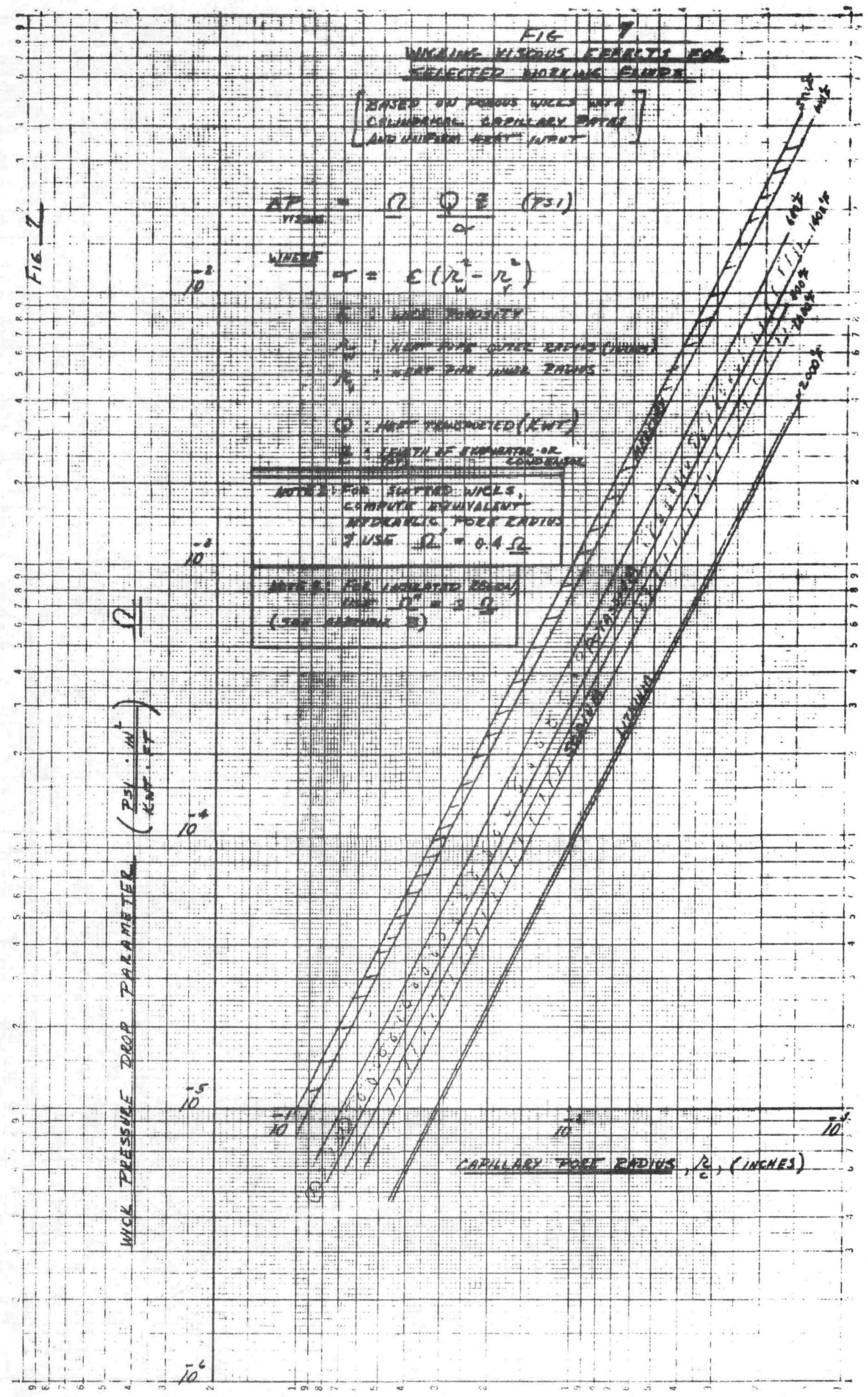




\section{Fi6 8 \\ $\angle A 5 L$ MOZEL FOR AXMAL DROFLE OF DRESTLEA WU VAPOR}

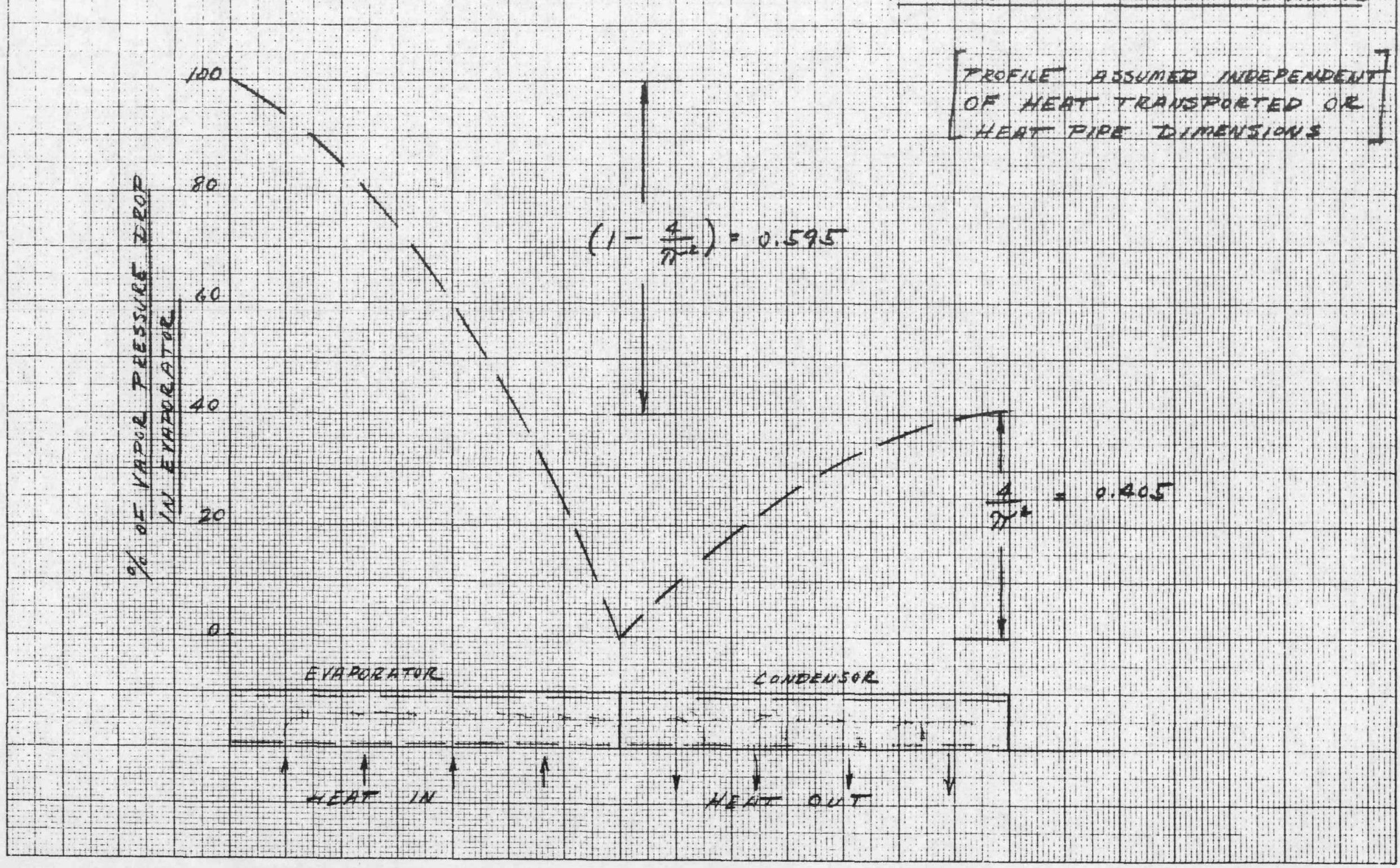




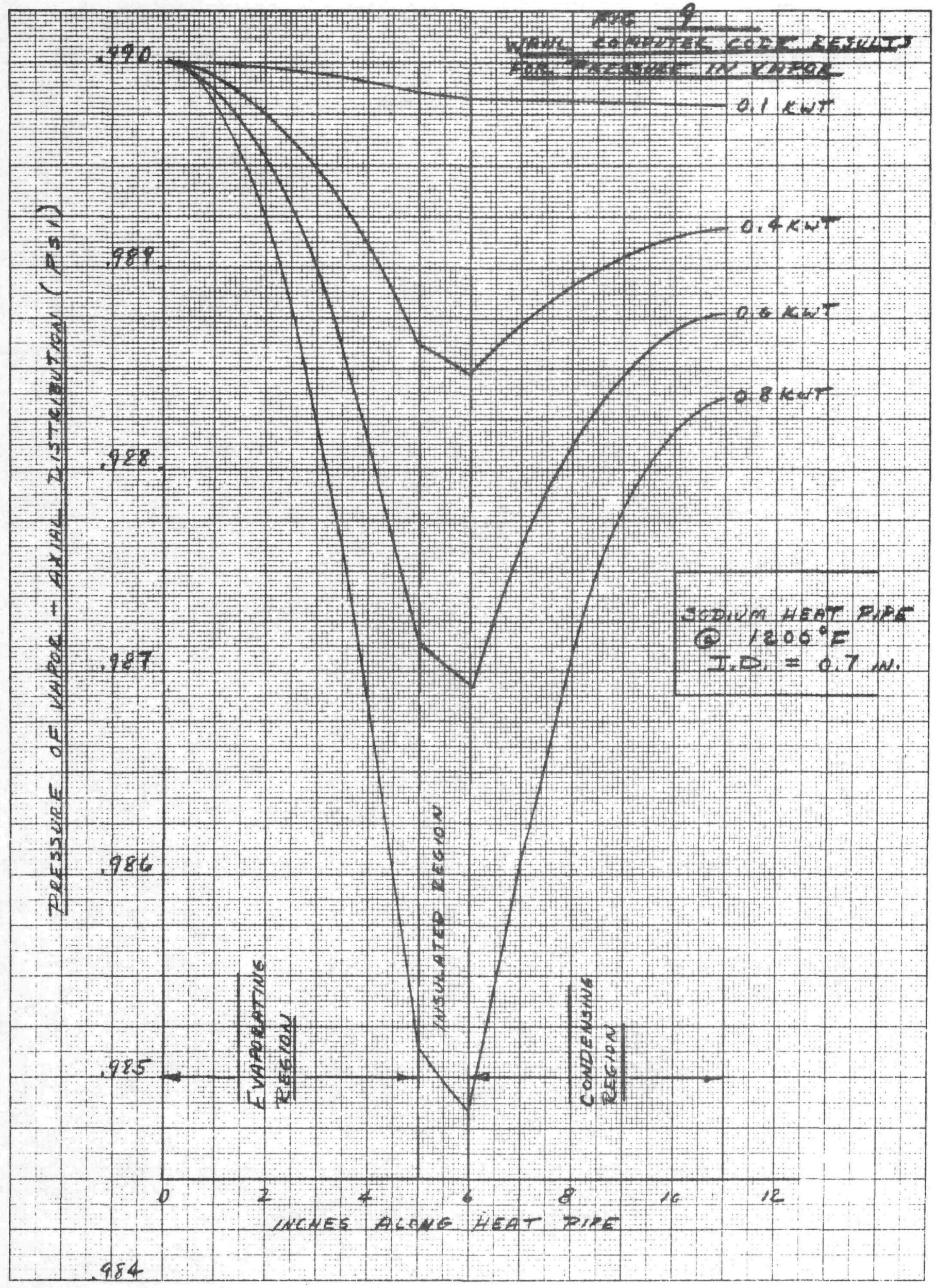




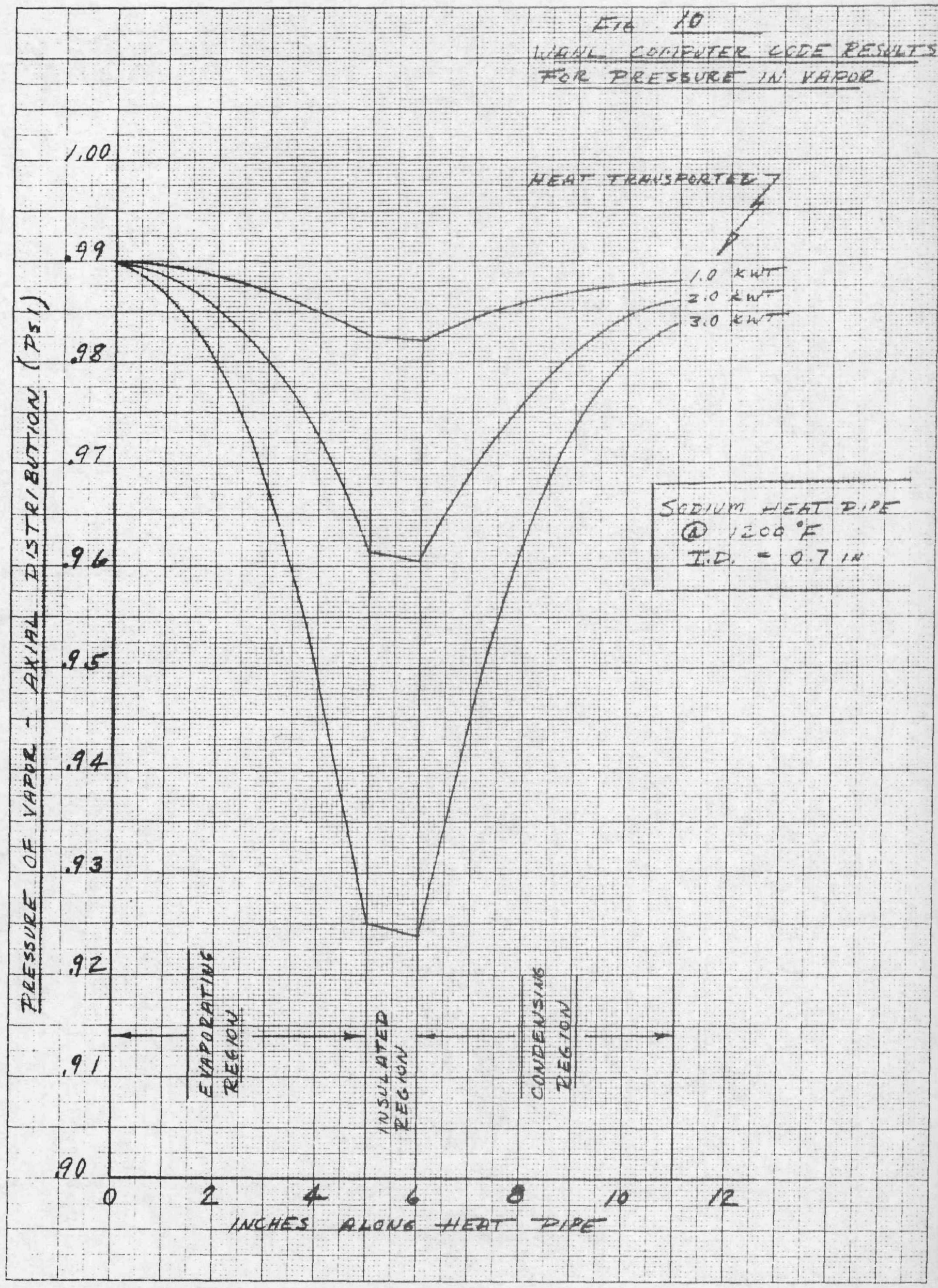




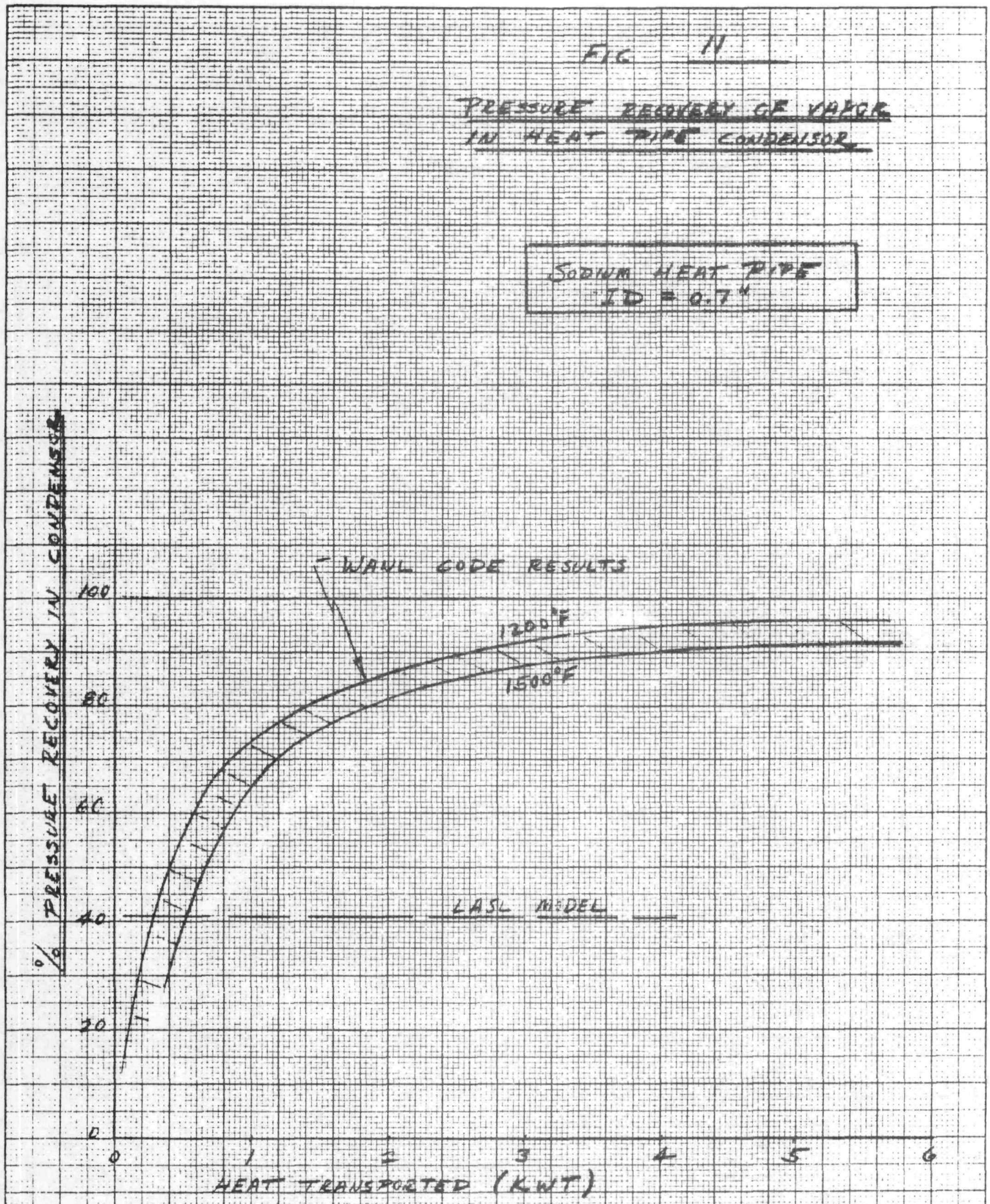




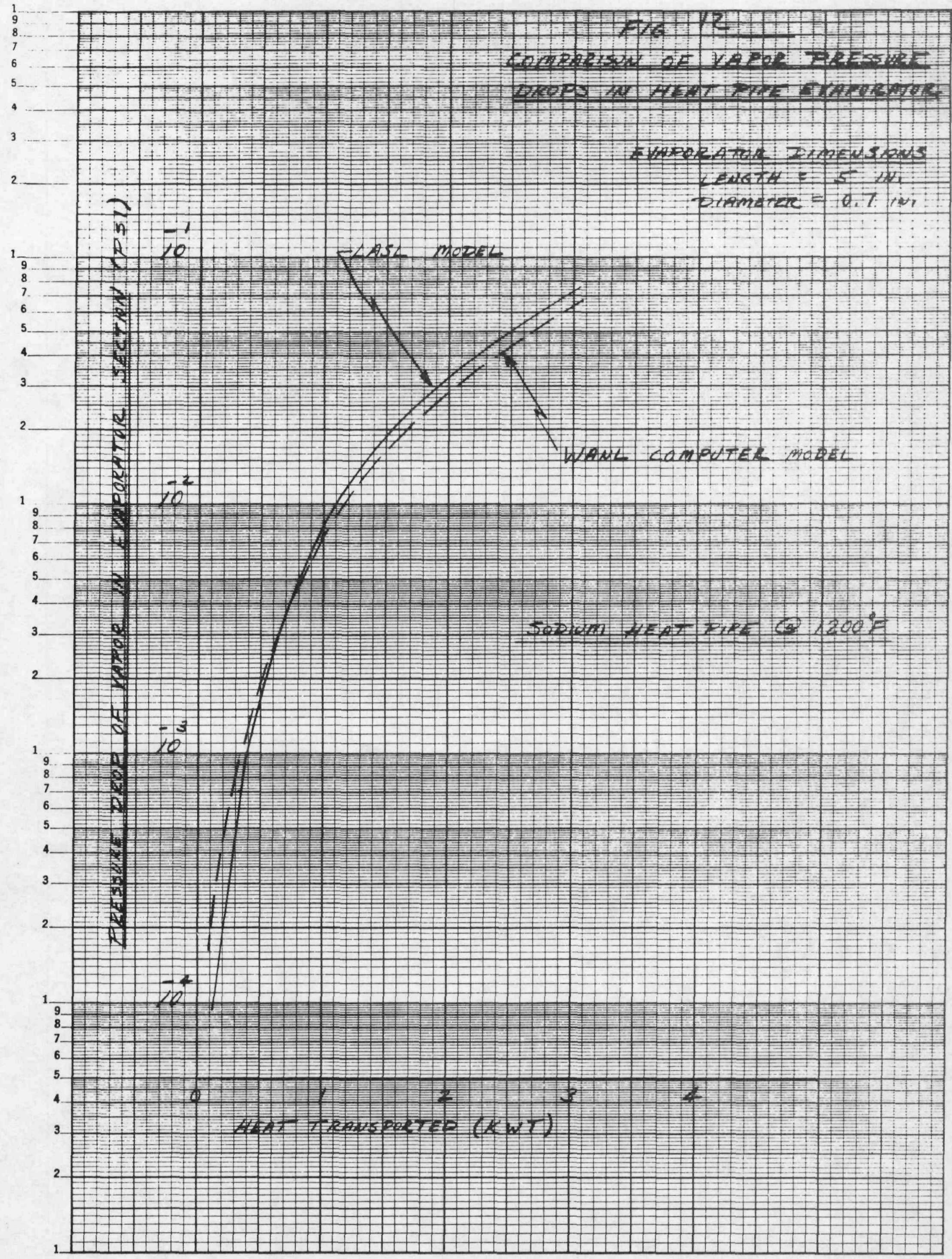




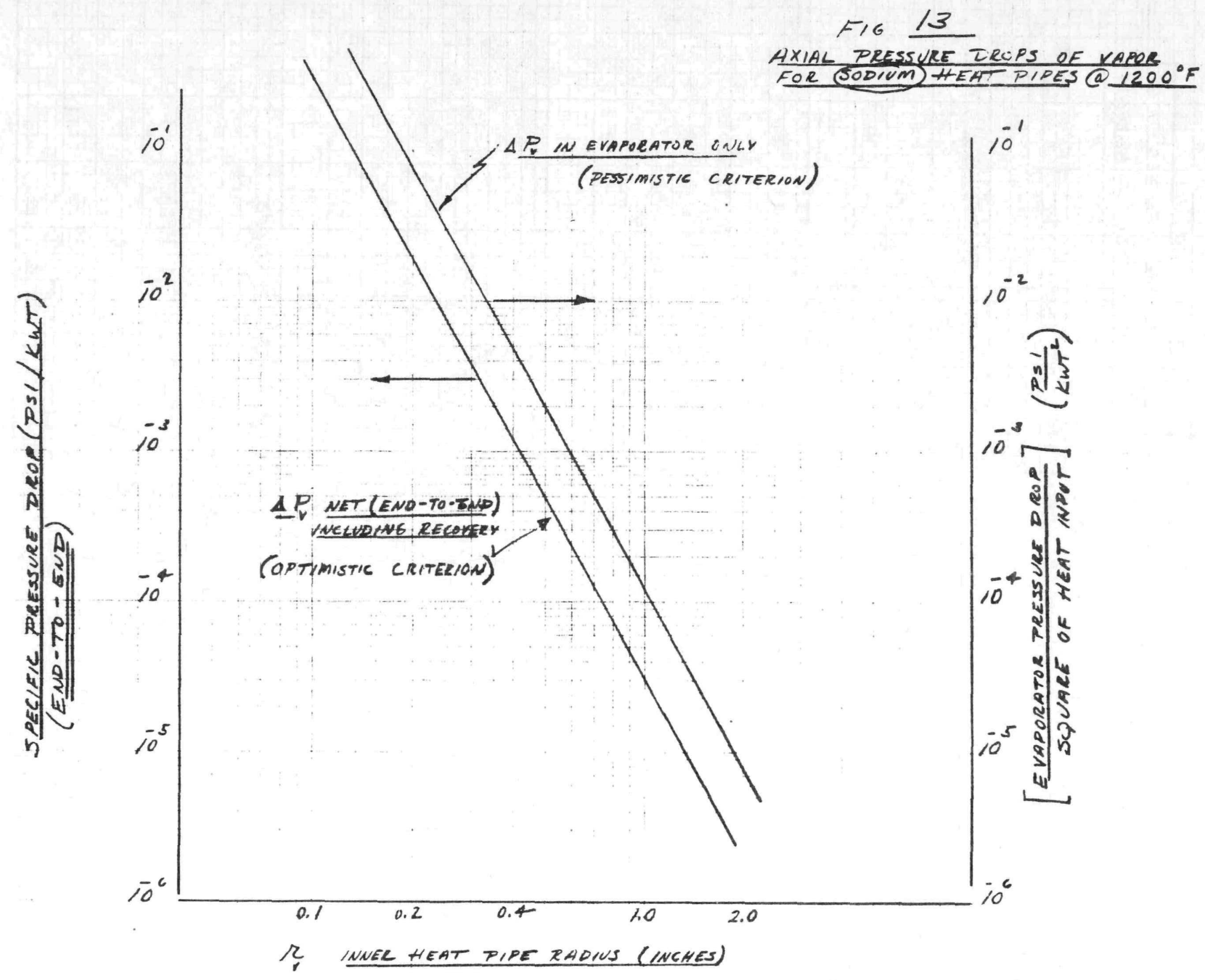




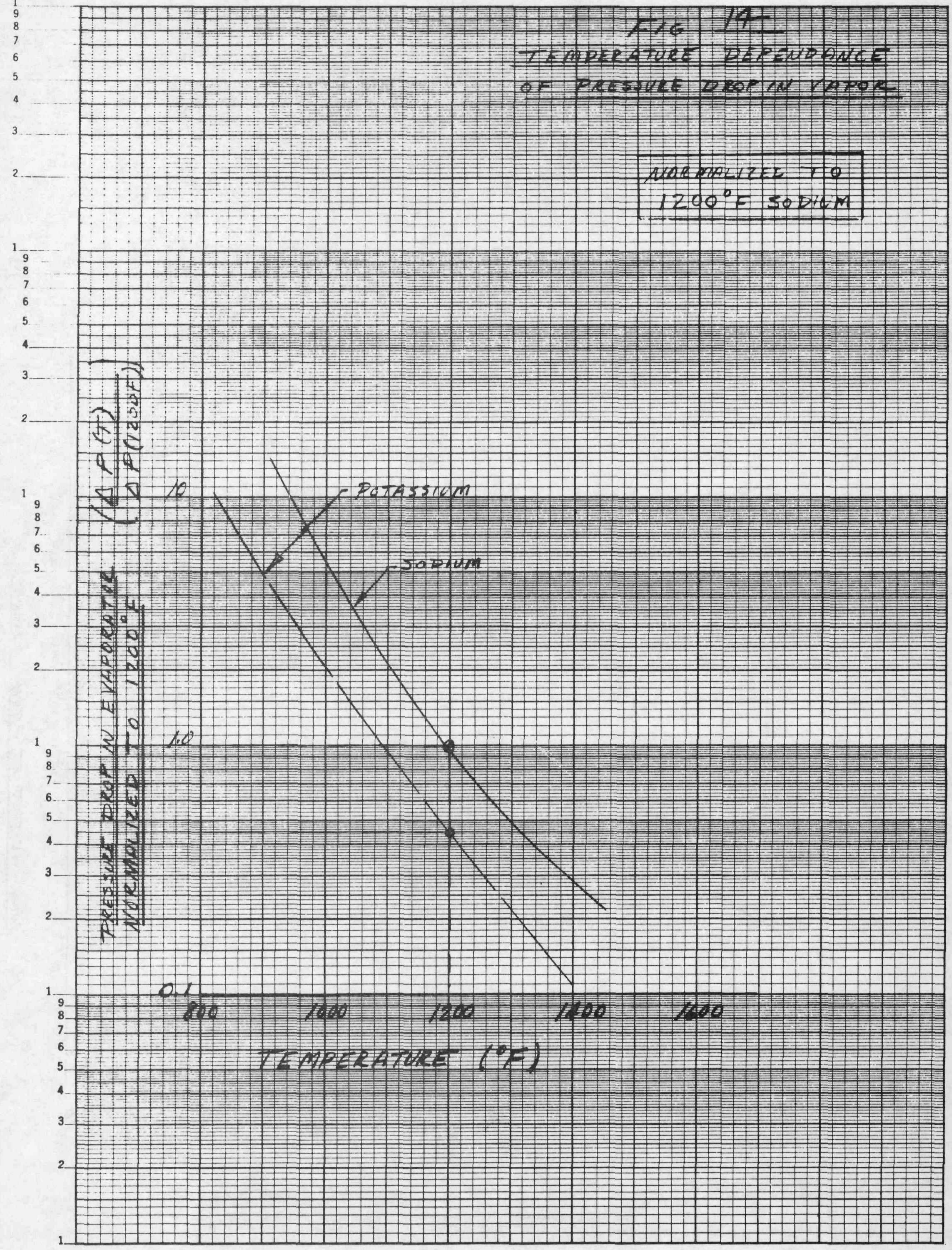




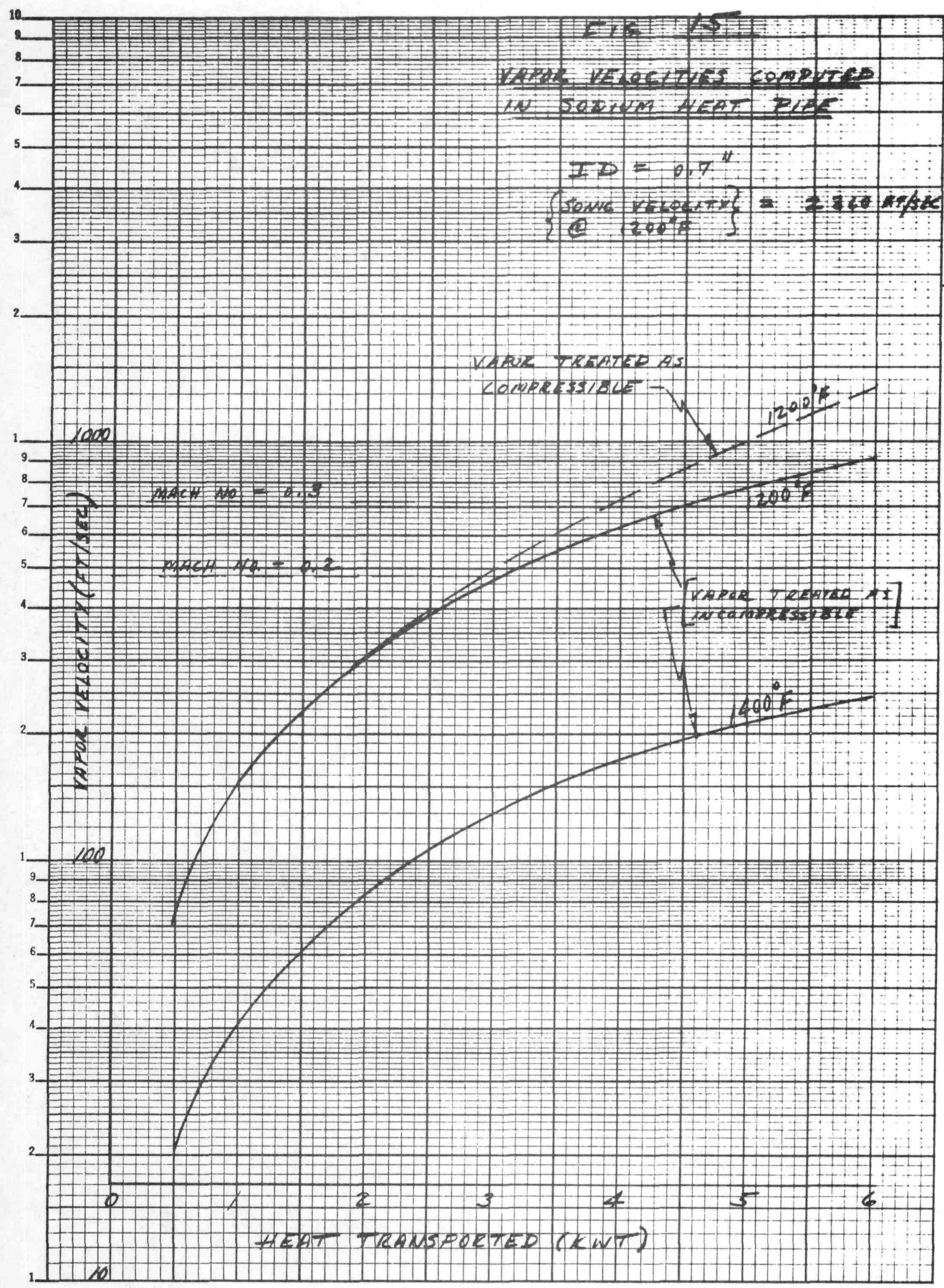




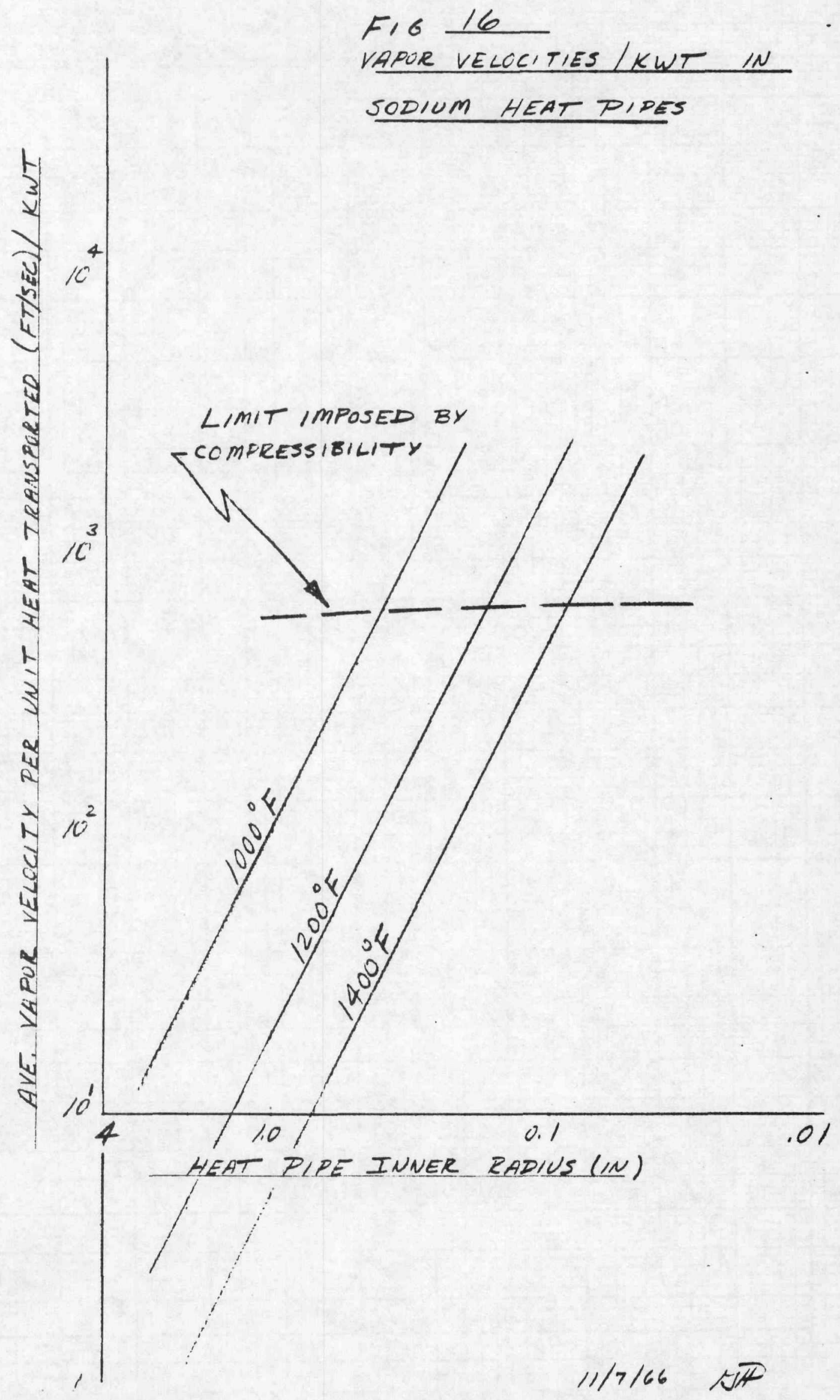




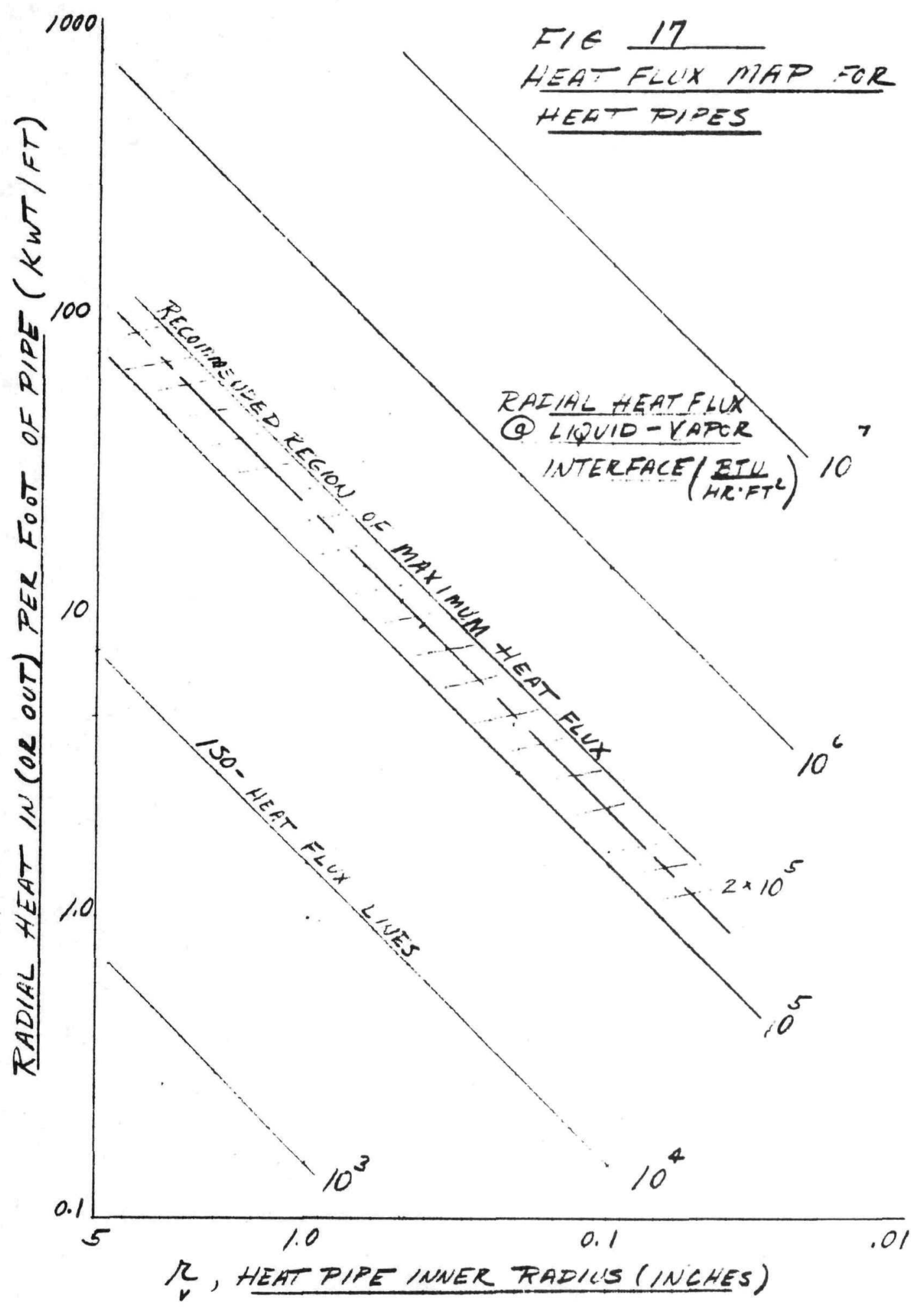

$$
G \mp 11 / 3 / 16
$$




\section{APPENDIX A \\ Derivation of Equivalent Hydraulic Pore Radius}

The "ideal" or classical capillary pore radius is cylindrical with radius, $r_{c}$. A fluid wetting this pore with contact angle will have a pressure difference across the meniscus equal to $\frac{2 \gamma \cos \theta}{r_{c}}$, where $\gamma$ is the surface tension (Figure $A-1$ ).

For wicking materials used in heat pipes, a porous or screened wick can be specified, in first approximation, by the average pore radius. In reality, the wick will be made up of a distribution of pore radii, and this should be accounted for if small effects are being sought.

The slotted or grooved type of wick is also used in heat pipes in which slots are fabricated into the inner wall of the pipe. An equivalent hydraulic pore radius, $r_{h}$, can be defined in conjunction with the slotted wick for use in design and parametric calculations.

Consider a grooved wick with individual slots of width $\Delta$ and height $H$. (Figure A-2).

The equivalent hydraulic pore radius can be defined as,

$$
\begin{aligned}
& r_{h}=\frac{\text { cross sectional flow area }}{\text { wetted perimeter }} \\
& r_{h}=\frac{\Delta H}{2 H+\Delta}=\frac{\Delta}{2+\frac{\Delta}{H}}
\end{aligned}
$$

It can be seen from Figure A-3 that, for values of $\frac{H}{\Delta}>5$, the equivalent pore radius $r_{h}$ approaches $\frac{\Delta}{2}$, the half-width of the slot. Therefore, the importance of computing $r_{h}$ occurs only when the ratio of slot height $H$ to slot width $\Delta$ is less than 10 . For higher ratios of $H / \Delta$, the correction is negligible and the pore radius can be taken as the half width $\Delta / 2$. 
(2) Astronuclear

Figure $A-1$

Figure $A-2$
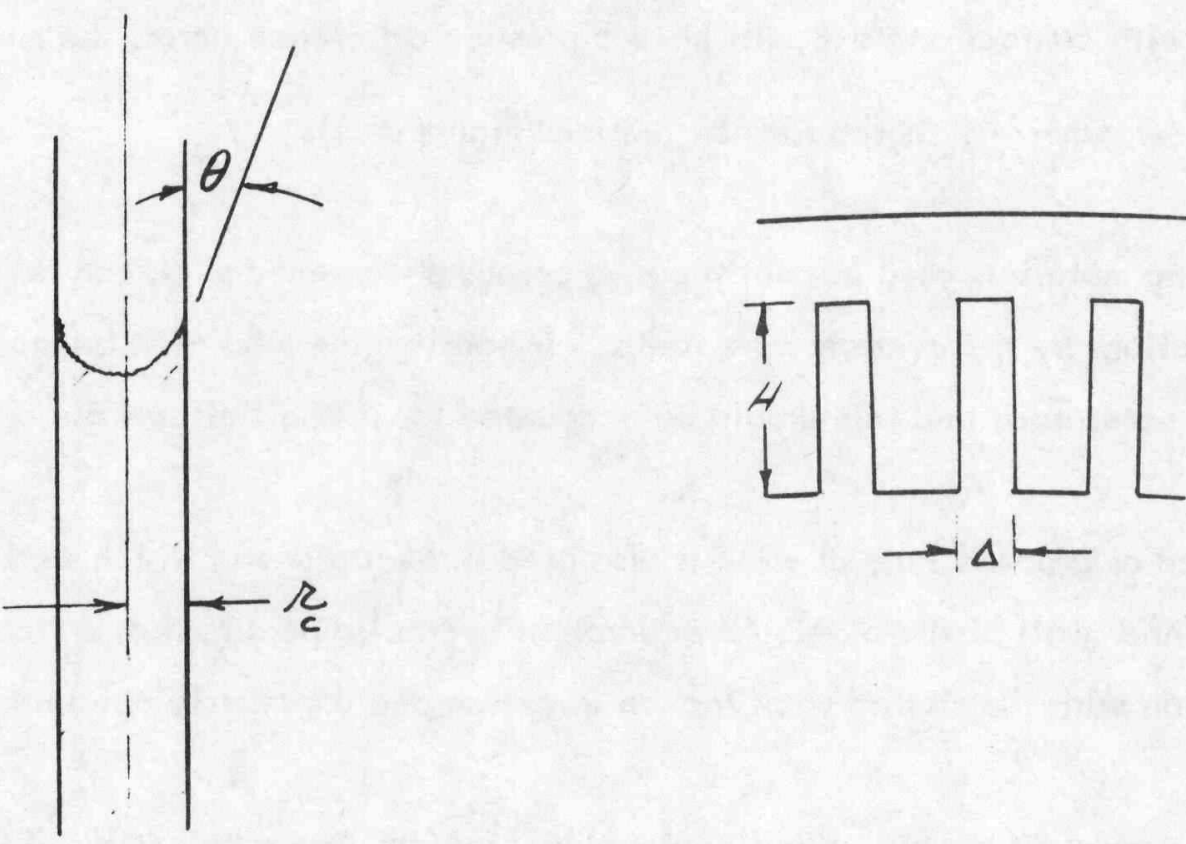

A-2 
1
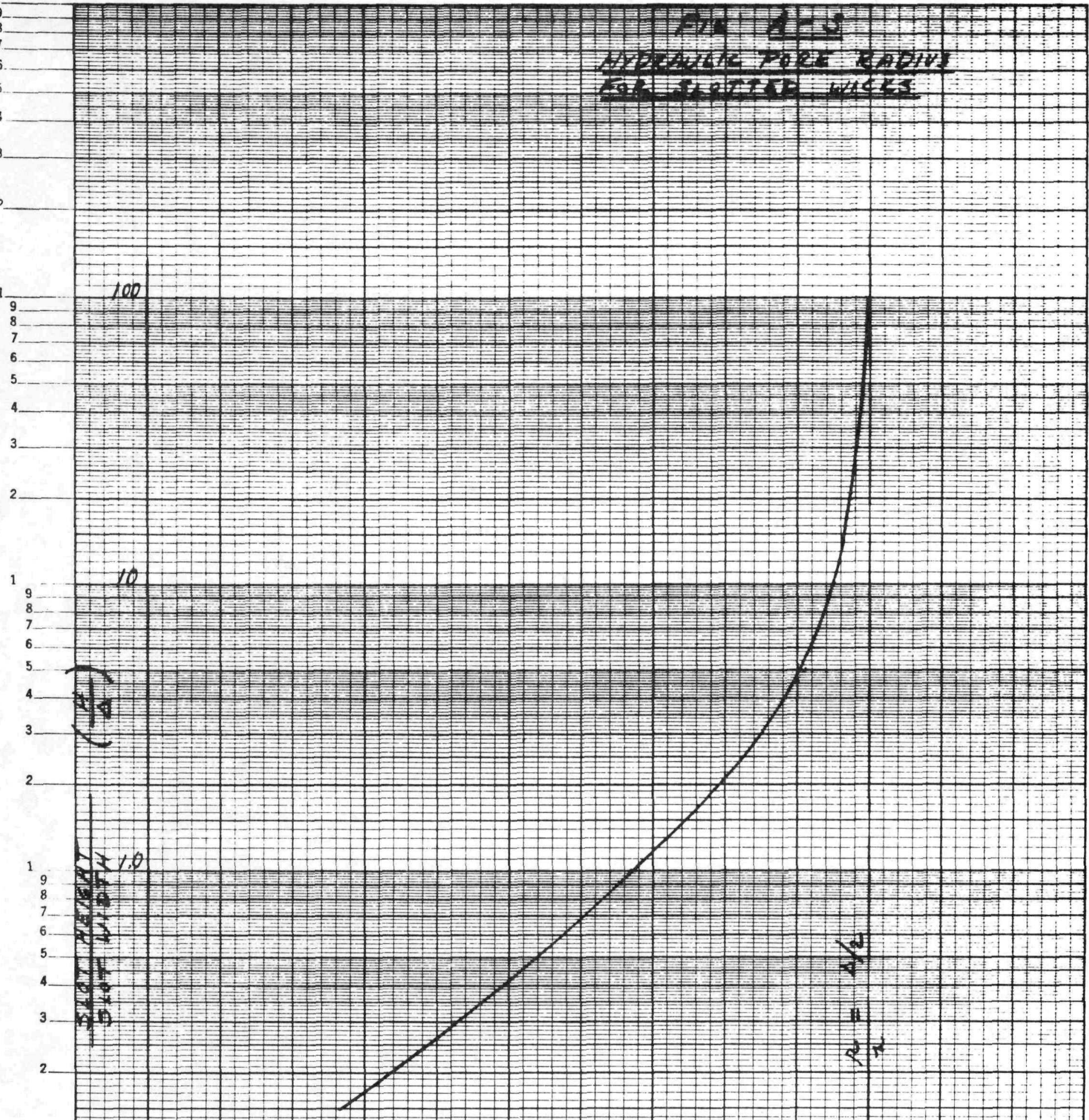

$1 . \quad 0.4$

8

7

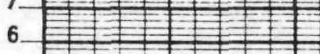

4.

3

2.

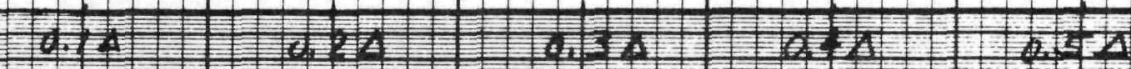

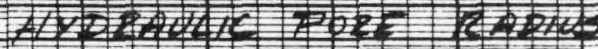

12

3

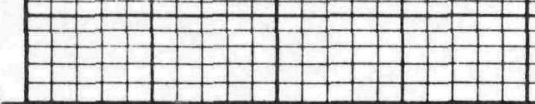




\section{APPENDIX B}

Integration of Liquid (Wick) Pressure Drop for Uniform Flux

Cotter has derived, from the Hagen-Poiseuille law for laminar flow of a fluid in a tube, an equation for the liquid pressure gradient in a heat pipe capillary wick:

$$
\frac{d P_{f}(z)}{d z}=\theta \dot{m}(z)
$$

where

$$
\theta=\frac{b \eta_{e}}{\pi\left(r_{w}^{2}-r_{v}^{2}\right)_{p_{l}} \in r_{c}^{2}}
$$

describes the wick dimensions and liquid properties. For purposes of this analysis, $C$ can be taken as constant, i.e., a specified wick configuration. $m_{l}(z)$ is the mass flow rate of liquid $(\mathrm{lb} / \mathrm{sec})$ at any axial point $z$ along the wick. Whenever the heat input and removal along the heat pipe are axially uniform, $(\mathrm{Kwt} / \mathrm{ft})$ but not necessarily equivalent, the axial profile of liquid flow rate will increase linearly to the interface between evaporator and condenser, then decrease linearly to the end of the condenser. If an insulated region separates the evaporator and condenser, the flow rate will be constant in this region.

The profile is shown in Figure B-1. The total flow rate occurs in the insulated region and equals the total heat transported divided by the fluid's latent heat of vaporization. 
TABLE B-1

\begin{tabular}{|l|c|c|c|}
\hline \multicolumn{2}{|c|}{ Region of Heat Pipe } & $\begin{array}{l}\text { Liquid Flow } \\
\text { Rate } m_{\ell}(z)\end{array}$ & Pressure Drop in Wick \\
\hline Evaporator & $0 \leq z \leq a$ & $\frac{z}{a} \frac{Q}{L}$ & $p(a)-p(0)=\frac{\theta Q}{2 L} a$ \\
Insulated & $a \leq z \leq c$ & $Q / L$ & $p(c)-p(a)=\frac{\theta Q}{L}(c-a)$ \\
Condenser & $c \leq z \leq \ell$ & $\left(\frac{\ell-z}{\ell-c}\right) \frac{Q}{L}$ & $p(1)-p(c)=\frac{\theta Q}{2 L}(l-c)$ \\
\hline
\end{tabular}

The profile shown in Figure B-1 is algebraically described in Table B-1. Using these descriptions of flow rate, the wick pressure drops in each segment can be computed by price-wise integration Eq. B-1. The results of these pressure drop integrations were used in preparing the parametric curves shown in Figure 7 of this report.

FIGURE B-1

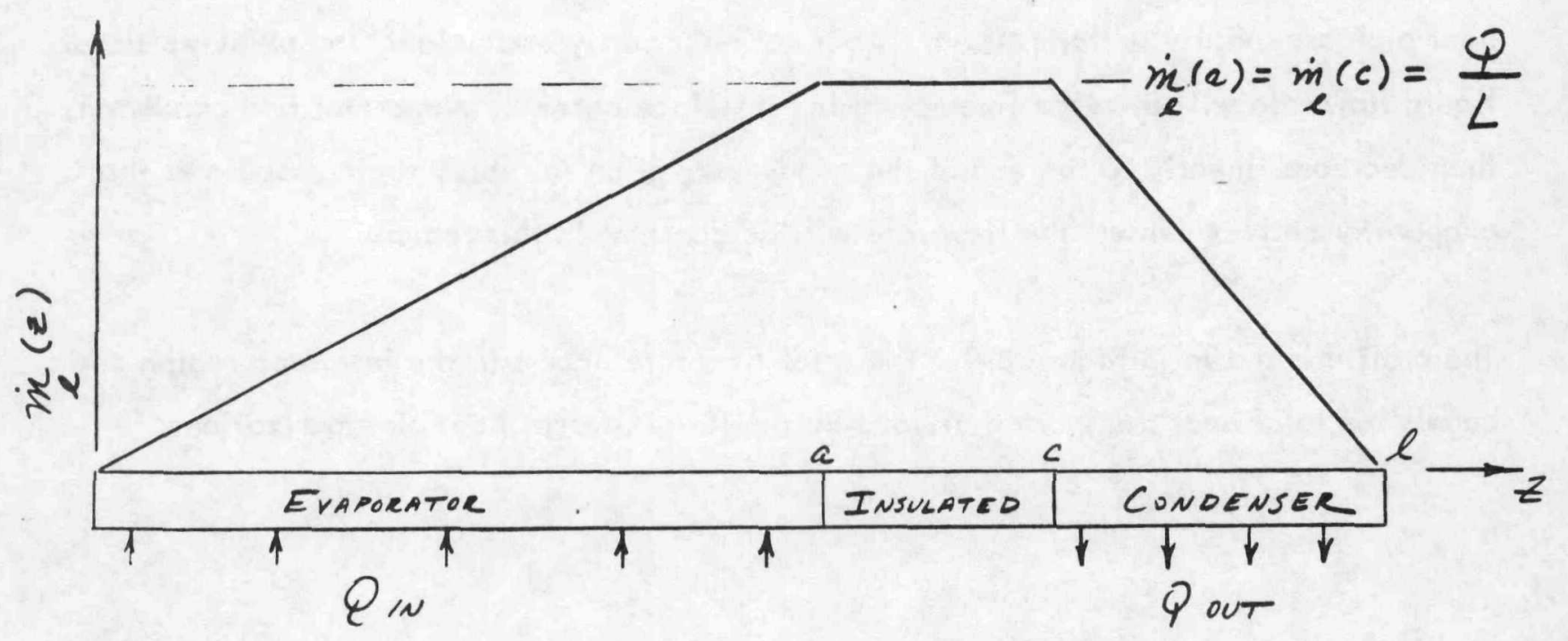


NOMENCLATURE FOR APPENDIX B

\begin{tabular}{|c|c|c|}
\hline$\eta$ & - & liquid viscosity \\
\hline b & - & wick geometrical constant \\
\hline w & - & heat pipe outer radius \\
\hline$r_{v}$ & - & heat pipe inner radius \\
\hline R & - & liquid density \\
\hline$r_{c}$ & - & capillary pore radius \\
\hline$z$ & - & variable distance along heat pipe \\
\hline$P_{\ell}(z)$ & - & liquid pressure at point $z$ \\
\hline$\dot{m}(z)$ & - & liquid mass flow rate \\
\hline
\end{tabular}




\section{APPENDIX C}

\section{Design Example}

Consider a heat pipe using sodium as the working fluid to be operated at $1200^{\circ} \mathrm{F}$. Assume an outer diameter of $1.7 \mathrm{~cm}(0.67 \mathrm{in}$.$) and a length requirement of 90 \mathrm{~cm}(2.95 \mathrm{ft}$.$) . The required$ condenser length is $30 \mathrm{~cm}$; the remaining $60 \mathrm{~cm}$ serves as the evaporator.

With the above fixed conditions, the object of the example is to determine reasonable estimates of the performance capabilities of the pipe. As a first approximation, assume an outer wall thickness of 0.020 in., and an inner diameter of 0.5 in. for vapor flow. Thus, the available wick thickness is $0.065 \mathrm{in}$.

The available capillary head is shown in Figure $\mathrm{C}-1$ as a function of pore radius by the two straight lines denoting perfect wetting $\left(\theta=90^{\circ}\right)$ and an arbitrary $\theta=60^{\circ}$, respectively.

It can be seen that for radii approaching $10^{-3}$ in., the capillary head can exceed 1 psi. Conversely, for radii approaching the thickness of the wick, .065 in., the head is small, .02 psi. These variations in head must equal or exceed the pressure drops in the wick and vapor regions. The sum of these drops is shown in Figure $\mathrm{C}-1$ for two cases: 1 and $2 \mathrm{Kwt}$ heat transport. For small pore radii, the liquid drop dominates, while for large radii the vapor drop dominates. The divergence in the curves as $r_{c} \sim 0.1$ in., represents the $\Delta P_{v}$ computed with the pessimistic and optimistic criteria respectively (see Section III-D).

From Figure $\mathrm{C}-1$ one can conclude that the best region for selecting a pore radius is .01 \pm $.005 \mathrm{in}$. At $1 \mathrm{Kwt}$, the heat pipe would have a margin of capillary pumping, while at $2 \mathrm{Kwt}$ the pressure limit is being reached. 


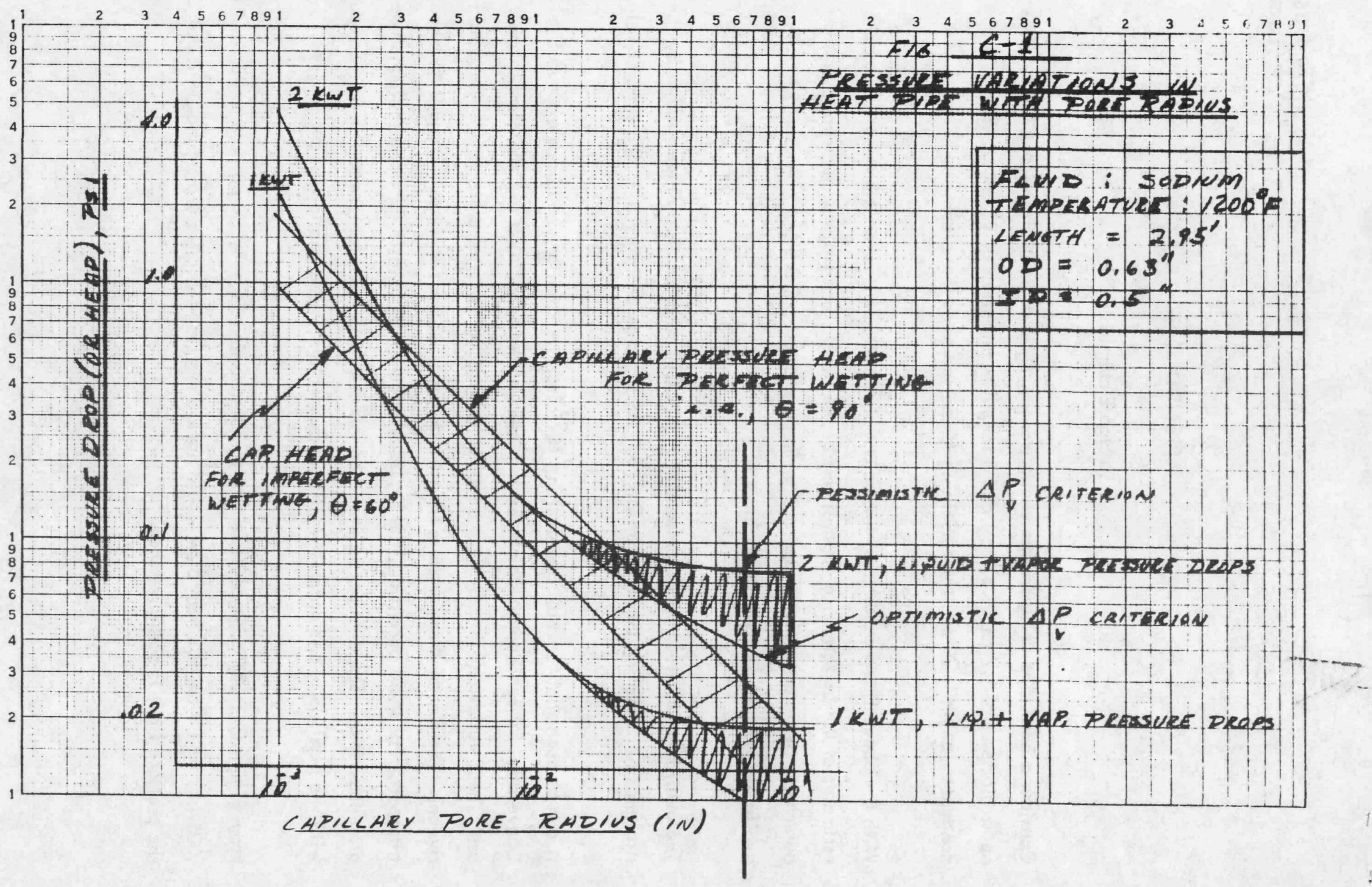

